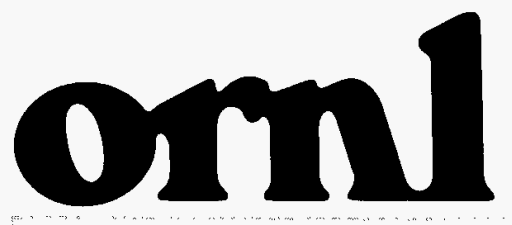

\section{OAK RIDGE} NATIONAL LABORATORY

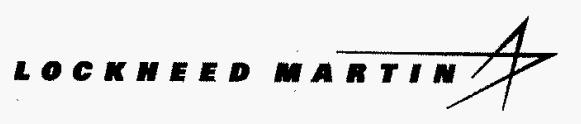

\section{Alternative Methods To Determine Headwater Benefits}

Yixing S. Bao

Robert D. Perlack

Michael J. Sale

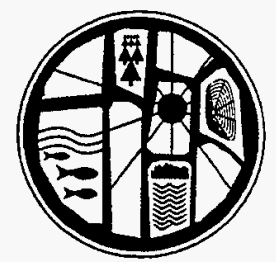


This report has been reproduced directly from the best available copy.

Available to DOE and DOE contractors from the Office of Scientific and Technical

Information, P.O.Box 62, Oak Ridge, TN 37831; prices available from (423) 576-8401, FTS 626-8401.

Available to the public from the National Technical Information Service, U.S. Department

of Commerce, 5285 Port Royal Rd., Springfield, VA 22161

This report was prepared a an account of work sponsored by an agency of the United States Govemment. Neither the United States Govemment nor any agency thereof, nor any of their employees, makes any warranty, express or implied, or assumes any legal liability or responsibility for the accuracy, completeness, or usefulness of any information, apparatus, product, or process disclosed, or represents that its use would not infringe privately owned rights. Reference herein to any specific commercial product, process, or service by trade name, trademark, manufacturer, or otherwise, does not necessarily constitute or imply its endorsement, recommendation, or favoring by the United States Govemment or any agency thereof. The view and opinions of authors expressed herein do not necessarily state or reflect those of the UnitedStatesGovemment or any agency thereof. 


\title{
ALTERNATIVE METHODS TO DETERMINE HEADWATER BENEFITS
}

\author{
Prepared by \\ Yixing S. $\mathrm{Bao}^{\dagger}$ \\ Robert D. Perlack ${ }^{\ddagger}$ \\ Michael J. Sale ${ }^{\dagger}$ \\ Environmental Science Division
Energy Division $^{\dagger}$
Oak Ridge National Laboratory
}

November 10, 1997

Prepared for the

Federal Energy Regulatory Commission

Office of Hydropower Licensing

Division of Project Compliance and Administration

\author{
Prepared by \\ Oak Ridge National Laboratory \\ Oak Ridge, TN 37831-6285 \\ managed by \\ for the \\ U.S. Department of Energy

Lockheed Martin Energy Research Corp.

under contract number DE-AC05-96OR22464 


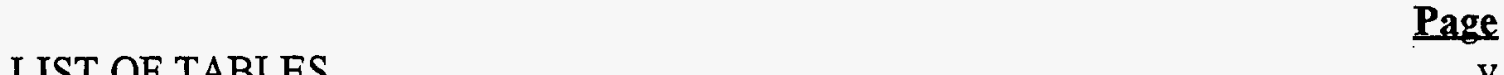

LIST OF FIGURES $\ldots \ldots \ldots \ldots \ldots \ldots \ldots \ldots \ldots \ldots \ldots \ldots \ldots \ldots \ldots \ldots$ vii

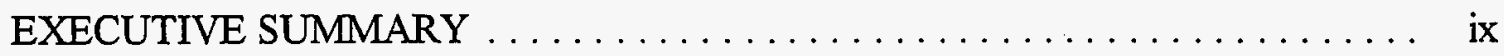

1. INTRODUCTION . . . . . . . . . . . . . . . . . . . . . . . 1

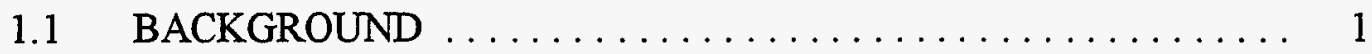

1.2 PURPOSE AND ORGANIZATION $\ldots \ldots \ldots \ldots \ldots \ldots \ldots, 2$

2. OVERVIEW OF METHODS TO CALCULATE ENERGY GAINS . . . . . 4

2.1 HEADWATER BENEFITS ENERGY GAINS MODEL . . . . . . 4

2.2 FLOW DURATION ANALYSIS METHODOLOGY $\ldots \ldots \ldots \ldots 6$

2.2.1 Adjustments and Data Considerations ............. 9

2.2.2 Power Generation and Turbine Flow Considerations ....... 10

3. HWBEG MODEL COMPUTATION OF ENERGY GAINS USING DAIIY

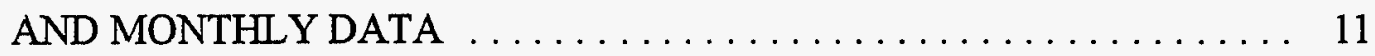

3.1 MODEL BACKGROUND $\ldots \ldots \ldots \ldots \ldots \ldots \ldots \ldots \ldots \ldots \ldots$

3.2 COMPARATIVE RESULTS $\ldots \ldots \ldots \ldots \ldots \ldots \ldots \ldots \ldots$

3.2.1 Daily and Monthly Energy Gains Comparisons . . . . . . . 13

3.3 CONCLUSIONS .......................... 18

4. DOCUMENTATION AND ENHANCEMENTS TO THE FDA METHOD . 19

4.1 VERIFICATION OF THE FDA CALCULATED ENERGY GAINS . 19

4.2 DEVELOPMENT OF ENHANCED FDA METHOD . . . . . . . . . 19

4.2.1 Effects of Simulated Unregulated Flows ............. 21

4.3 RESULTS AND ANALYSES USING ENHANCED FDA METHOD 21

4.3.1 Effects of Flow Step Increment ............... 21

4.3.2 Effects of Length of Data Record ............... 22

4.3.3 Effects of a Variable Flow-head-efficiency Relationship . . . . . 27

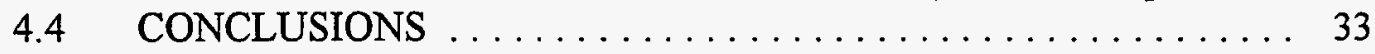

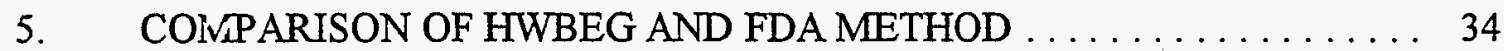

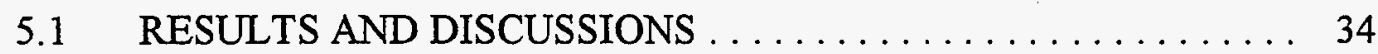

5.1.1 Modification of FDA to Derive Unregulated Flow Data . . . . 34

5.1.2 Application of Modified FDA Method to Tulloch

Hydropower Plant . . . . . . . . . . . . . . . . . . . 34 


\section{CONTENTS (continued)}

\subsection{FACTORS AFFECT ESTIMATING HEADWATER BENEFITS}

Page

USING FDA METHOD $\ldots \ldots \ldots \ldots \ldots \ldots \ldots \ldots \ldots \ldots \ldots, 41$

5.2 .1 Length of data period $\ldots \ldots \ldots \ldots \ldots \ldots \ldots \ldots \ldots, 41$

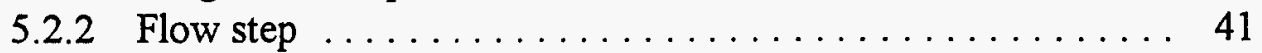

5.2 .3 Starting point for integral $\ldots \ldots \ldots \ldots \ldots \ldots \ldots \ldots, 41$

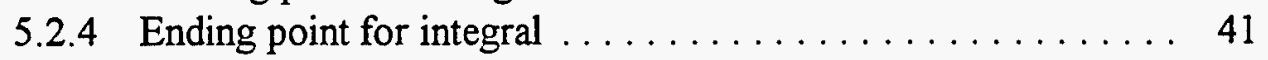

5.2 .5 Incorrect flow data $\ldots \ldots \ldots \ldots \ldots \ldots \ldots \ldots \ldots .44$

5.2.6 Constant flow-power ratio vs variable hydraulic head

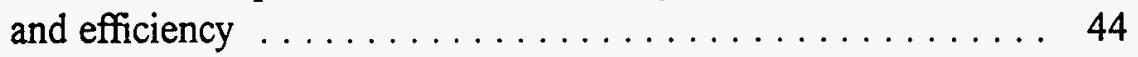

5.2 .7 Complexity of river system $\ldots \ldots \ldots \ldots \ldots \ldots \ldots \ldots \ldots 44$

5.3 CONCLUSIONS ........................... 44

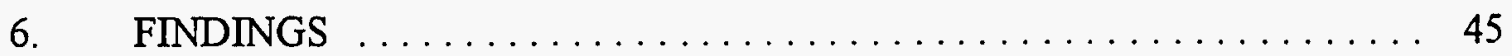

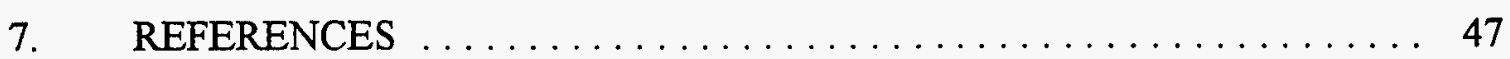

APPENDIX: COMPUTER CODE $\ldots \ldots \ldots \ldots \ldots \ldots \ldots \ldots \ldots \ldots \ldots .49$ 


\section{TABLES}

Table

Page

3.1 Summary comparison of energy gains for the Alabama River Basin (Lay bydropower project) and the Stanislaus River Basin (Tulloch hydropower project).

3.2 Comparison of daily and monthly energy gains calculations for the Logan Martin hydropower project in the Alabama River Basin (1974-1982).

3.3 Comparison of daily and monthly energy gains calculations for the Lay hydropower project in the Alabama River Basin (1974-1982) . . . . . . . . 16

3.4 Comparison of daily and monthly energy gains calculations for the Tulloch hydropower project in the Stanislaus River Basin (1979-1991).

4.1 Comparison of annual energy gains for Cushaw Hydro Station in James River

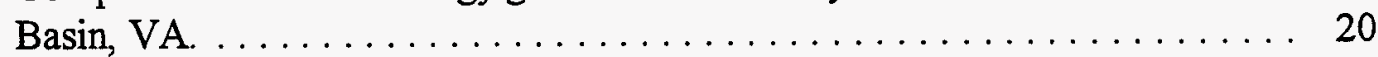

4.2 Effects of simulated unregulated flows on assessment of energy gains for Tulloch Power Plant ............................ 22

5.1 Input data file of HWBFDA to estimate Headwater Benefits for Tulloch hydropower plant in Stanislaus River Basin, CA. . . . . . . . . . 36

5.2 Input data file of HWBFDA to estimate Headwater Benefits for Lay hydropower plant in Alabama River Basin, AL.. . . . . . . . . . . 36

5.3 Input data file of HWBFDA to estimate Headwater Benefits for Logan Martin hydropower plant in Alabama River Basin, AL. . . . . . . . . . 37

5.4 Comparison of energy gains calculated using HWBEG and enhanced FDA methods. 


\section{FIGURES}

Figure

2.1. Construction of flow duration curve from streamflow hydrograph. . . . . . 7

2.2. Example of before and after flow duration curve ............. 8

3.1. Schematic representation of the Alabama and Stanislaus River Basins. . . . . 12

4.1. Impact of flow increment on calculation of energy gains for Cushaw Hydropower Plant in the James River Basin based on water year data points. . 23

4.2. Impact of flow increment on calculation of energy gains for Cushaw Hydropower Plant in the James River Basin based on water year data points. . 24

4.3. Comparison of energy gains using water-year and calendar-year data for Cushaw Hydropower Plant. . . . . . . . . . . . . . . . . . . 25

4.4. Annual flow duration curve for Cushaw Hydropower Plant adjusted for drainage area based on USGS station 02025500 Holcomb Rock, James River. ................................ 26

4.5. Comparison of energy gains using flow power ratio and variable flow headefficiency for Cushaw Hydropower Plant. . . . . . . . . . . . . . . 28

4.6. Comparison of power generation between flow-power ratio and actual performance curves for Cushaw Hydropower Plant. . . . . . . . . . . . . . 29

4.7. Number of generators in operation and flow-stage relationship for Cushaw Hydropower Plant. ........................ 30

4.8. Combined efficiency curve and power generation for Cushaw Hydropower Plant. . . . . . . . . . . . . . . . . . . . 31

4.9. Performance of turbine-generator unit corresponding to hydraulic head of 26,27 , and 28 feet at the Cushaw Hydropower plant. . . . . . . . . 32

5.1. Annual flow duration curve for the Tulloch Hydropower Plant adjusted for drainage area based on USGS station 11299500, Stanislaus River (0 to $2,200 \mathrm{cfs}$ flow range).

5.2. Annual flow duration curve for the Tulloch Hydropower Plant adjusted for drainage area based on USGS station 11299500, Alabama River (0 to 40,000 cfs flow range). . . . . . . . . . . . . . . . . . .

5.3. Annual flow duration curve for the Lay Hydropower Plant adjusted for drainage area based on USGS station 02407000 , Alabama River (0 to 160,000 cfs flow range).. . . . . . . . . . . . . . . . . . .

5.4. Annual flow duration curve for the Lay Hydropower Plant adjusted for drainage area based on USGS station 02407000 , Alabama River (0 to $40,000 \mathrm{cfs}$ flow range).

5.5. Annual flow duration curve for Logan Martin hydropower plant adjusted for drainage area based on USGS Station 02407000, Alabama River (0 to 40,000 cfs flow range)

5.6 Annual flow duration curve for Logan Martin hydropower plant adjusted for drainage area based on USGS Station 02407000, Alabama River (0 to 140,000 cfs flow range).. . . . . . . . . . . . . . . . . . 


\section{EXECUTIVE SUMMARY}

Under Section 10(f) of the Federal Power Act, the Federal Energy Regulatory Commission (FERC) is required to assess charges to downstream owners of non-federal hydropower projects that directly benefit from headwater improvements constructed by the U.S. or by a federal licensee. Headwater benefits are defined in the Code of Federal Regulations (CFR) as the additional energy (i.e., energy gains) derived from the flow regulating activities of the headwater project. The CFR requires that FERC use the Headwater Benefits Energy Gains (HWBEG) model to calculate energy gains, except for headwater benefits determinations that are not complex, or in which the headwater benefits are expected to be small. Because the HWBEG model operates on a daily time step, it requires significant staff time and resources to prepare the necessary data files and apply the model. Although the costs of making headwater benefits determinations are included in the assessments made to downstream beneficiaries, the use of the HWBEG model in basins that are not complex or where the magnitude of the benefits is expected to be small may not be warranted.

In 1992, the FERC began using a Flow Duration Analysis (FDA) methodology to assess headwater benefits in river basins where use of the HWBEG model may not result in significant improvements in modeling accuracy. The purpose of this study is to validate the accuracy and appropriateness of the FDA method for determining energy gains in less complex basins. This report presents the results of Oak Ridge National Laboratory's (ORNL's) validation of the FDA method. The validation is based on a comparison of energy gains using the FDA method with energy gains calculated using the HWBEG model. Comparisons of energy gains are made on a daily and monthly basis for a complex river basin (the Alabama River Basin) and a basin that is considered relatively simple hydrologically (the Stanislaus River Basin). In addition to validating the FDA method, ORNL was asked to suggest refinements and improvements to the FDA method. Refinements and improvements to the FDA method were carried out using the James River Basin as a test case.

The general finding of this study is that the FDA method is an appropriate method to determine energy gains in river basins that are not complex. In non-complex basins, such as the Stanislaus, the FDA method may provide a close approximation to an energy gain analysis using daily data and the HWBEG model. For a complex river-reservoir system such as the Alabama River Basin, the FDA method overestimated the annual energy gains. ORNL did not determine whether the FDA method is inappropriate for complex basins, or whether the differences in energy gains are due to data rather than the basic limitation of the method. The standard FDA procedures in use by FERC can be modified to automatic its use, to allow a smaller time step in the numerical integration, and to use a variable flow-head-efficiency relationship. These modifications are incorporated into an enhanced FDA method. 


\section{INTRODUCTION}

\subsection{BACKGROUND}

The Federal Energy Regulatory Commission (FERC) is required under Section 10(f) of the Federal Power Act to assess charges to downstream owners of non-federal hydropower projects that are directly benefited from headwater improvements constructed by the U.S. or by a federal licensee (CFR, 1994). The assessed charges are for an equitable portion of the annual Section 10(f) costs of interest, maintenance, and depreciation of the joint-use costs allocated to the power function of the headwater improvement. ${ }^{1}$

The Code of Federal Regulations (CFR-Sections 11.10-11.21, Title 18; amended June 26, 1986) provides regulatory guidelines and procedures for FERC to determine headwater benefits and to apportion the Section $10(f)$ costs among downstream owners of non-federal hydropower projects. Headwater benefits at a downstream project are defined in Title 18 of the CFR as the additional power generation that results from regulation of the streamflow by the headwater improvement (usually a storage reservoir). The presence of the headwater reservoir with the ability to regulate flow allows downstream project owners to generate more electricity than otherwise would be possible without the headwater project. Although the amount of water within the river basin does not change, the presence of the headwater improvement has the effect of levelizing streamflow-reducing occurrences of spills during high flow conditions and providing for more water during low flow conditions. The additional power generation or energy gains are calculated as the difference between the energy generated with and without the headwater improvement.

The annual charges to downstream owners are computed by multiplying the Section $10(f)$ costs by a ratio of the energy gains received at a downstream project to the sum of all energy gains.

Mathematically, annual payments are derived as follows:

$$
P_{n}=C_{p} \times \frac{E_{n}}{E_{j}+E_{d}}
$$

where:

$\mathrm{P}_{n}=$ annual payment to be made by owner of downstream project $n$ (or group of projects),

$\mathrm{C}_{p}=$ annual headwater costs to be apportioned,

$\mathrm{E}_{n}=$ energy gains received at downstream project $n$,

$\mathrm{E}_{d}=$ annual energy gains received at all downstream projects, ${ }^{2}$ and

\footnotetext{
${ }^{1}$ The Federal Power Act also requires that FERC include the costs of determining the headwater benefits in the assessed charges.

${ }^{2}$ Owners of downstream projects with less than $1.5 \mathrm{MW}$ of installed generating capacity or for which the FERC has granted an exemption are not required to pay headwater benefits charges.
} 
$\mathrm{E}_{j}=$ portion of the annual generation at the headwater project assigned to the joint-use power cost. ${ }^{3}$

The CFR (Section 11.11) also states that annual payments or the charges assessed to a downstream owner cannot exceed $85 \%$ of the value of energy gains, excluding the costs of conducting the investigation. The value of energy gains is defined as the cost of acquiring an equivalent amount of electricity from the most likely alternative source during the assessment period.

Energy gains at a downstream project are determined by simulating operation of the project with and without the effects of headwater project. The CFR specifically requires the FERC to use the Headwater Benefits Energy Gains (HWBEG) model in calculating energy gains. ${ }^{4}$ However, the CFR gives FERC some flexibility to compute energy gains in situations in which determinations are not complex or where headwater benefits are expected to be small. In these situations, FERC has opted to use a Flow Duration Analysis (FDA) approach to determine energy gains.

\subsection{PURPOSE AND ORGANIZATION}

FERC uses a documented and validated computer model (HWBEG) for making determinations and assessing headwater benefits in larger river basins. The HWBEG model operates on a daily time step and requires significant staff time and resources to collect, prepare the necessary data files, and use the model. Although the costs of making headwater benefits determinations are included in the assessments made to downstream beneficiaries, the use of the HWBEG model in basins that are not complex or where the magnitude of the benefits is expected to be small may not be warranted. In some situations, the cost of making the determination using the HWBEG model could actually exceed the value of the energy gains received by downstream project owners.

In 1992, the FERC began using Flow Duration Analysis (FDA) to assess headwater benefits in river basins where use of the HWBEG model may not result in significant improvements in modeling accuracy. The purpose of this study is to validate the accuracy and appropriateness of the FDA method for determining energy gains in basins that are not complex or where headwater benefits are expected to be small. Our validation of the FDA method is based on an explicit comparison of energy

${ }^{3}$ The portion of the annual generation assigned to the joint-use power $\operatorname{cost}\left(E_{j}\right)$ is the product of the total annual generation at the headwater site and the ratio of the project investment cost assigned to the joint-use power cost to the sum of the investment cost assigned to both the specific power cost and the joint-use power cost:

$$
E_{j}=E \times \frac{C_{j}}{C_{s}+C_{j}}
$$

where:

$E_{j}=$ annual energy at the headwater site attributed to the joint-use power cost,

$E=$ total annual generation at the headwater site,

$\mathrm{C}_{\mathrm{j}}=$ project investment costs assigned to the joint-use power cost, and

$\mathrm{C}_{\mathrm{s}}=$ project investment costs assigned to specific power costs.

Definitions of the cost components can be found in the CFR (Title 18). More discussion of the method used to allocate joint-use power costs can be found in Perlack et al. (1984).

${ }^{4}$ The CFR prior to those amended June 26, 1986 referred to power benefits and power gains, but did not define these terms and how they are to be used in actual determinations. 
gains calculations with the HWBEG model using both daily and monthly data. ${ }^{5}$ We also suggest refinements and improvements in how the FDA method can be used in headwater benefits investigations. The James, Alabama, and Stanislaus River Basins are used throughout this evaluation.

Section 2 of our validation report provides a general overview of the two methods currently used by FERC to calculate energy gains-the HWBEG model and the standard FDA method. In Section 3, we use the HWBEG model to compute daily and monthly energy gains for representative downstream projects in the Alabama and Stanislaus River Basins and to compare these results with energy gains determined independently by FERC. This is done to ensure that we have a correct baseline for subsequent comparison with FDA-computed energy gains. In Section 4, we do a similar exercise with thestandard FDA method. That is, we use the FDA method to calculate energy gains and compare our results with energy gains published by the FERC for the James River Basin. This section also describes a number of enhancements we made to the FDA method. The fifth section reports on the energy gains calculations made using the FDA method for the Alabama and Stanislaus River Basins and the comparison of these results with energy gains determined with the HWBEG model. In the final section of the report we provide general conclusions and specific recommendations on use of the FDA method. Appendix A lists the computer code developed specifically to apply the enhanced FDA method to caiculate energy gains for James, Alabama, and Stanislaus River Basins.

${ }^{5}$ The monthly data were used in HWBEG to make preliminary evaluations of potential benefits in which there is a high degree of regulation and the released flows are relatively uniform. 


\section{OVERVIEW OF METHODS TO CALCULATE ENERGY GAINS}

This chapter provides a general overview of the two main approaches that FERC uses to determine energy gains-the Headwater Benefits Energy Gains (HWBEG) model and the flow duration analysis (FDA) method.

\subsection{HEADWATER BENEFITS ENERGY GAINS MODEL}

The HWBEG model was developed to calculate daily energy gains. ${ }^{6}$ The model uses both reservoir operating rules and hydropower plant rating equations to determine power generated under the presence and a.bsence of upstream flow-regulating reservoirs. The HWBEG model is data intensive and requires daily data on streamflow, storage changes at reservoirs, and power generated at hydro facilities.

In calculating energy gains at a particular downstream site, the model first eliminates the storage effects of all upstream reservoirs to simulate the unregulated or natural flow condition. The storage effects of upstream reservoirs on the downstream facility being investigated are then added back to the unregulated flow condition in a sequence corresponding to the initial date of filling. Since the upstream storage effects do not impact immediately on the downstream hydropower plant, all upstream effects are lagged to correspond to the time it takes the regulated flow to reach the downstream hydropower plant. As each reservoir is added back to the river system, the change in hydropower generation attributable to the particular flow condition is labeled as the energy gain attributable to the reservoir. Calculations for a particular downstream hydropower plant are made until all the reservoirs have been added back to the system. This same energy gain calculation process is repeated for all downstream hydropower facilities.

The first step in using the HWBEG model to calculate energy gains begins with the assembly of the requisite data files. Streamflow and storage change data are assembled for all reservoirs and generation and outage data are collected for all hydropower plants in the river basin. The streamflow, generation, and storage change data are merged for all facilities in the river basin into a master data file. The master data file and generator outage data are then used to develop a set of rating curves for each hydropower facility to be investigated for energy gains. The flow and storage change data in the master data file, as well as the reservoir operation rule curves, are used to develop empirical reservoir operating procedures for all storage reservoirs in the river basin.

The hydropower facilities, storage reservoirs, and the river basin are represented by a network system of nodes and branches in the HWBEG model. The branches connecting the nodes are numbered and are characterized by an integer lag time representing the time it takes in days for water to flow over the branch length. The model uses this node and branch representation of the river basin to assemble the unregulated and regulated inflows, to invoke reservoir operating rules in proper sequence, to

\footnotetext{
${ }^{6}$ This section provides a cursory overview of the HWBEG model. Detailed discussion can be found in the HWBEG model description and model evaluation (Perlack et al., 1984a; Turhollow et al., 1985). These studies were sponsored by DOE's Energy Information Administration for FERC to review and expand documentation to the HWBEG model; evaluate, modify, and enhance the model specification; validate the computer code for accuracy; and assess input data and all statistical operations. A microcomputer version of the HWBEG model and associated documentation was completed in 1993 (FERC, 1993a).
} 
calculate power generation at hydropower facilities, and to calculate energy gains for all downstream projects benefitted from flow regulation.

The output from the HWBEG model consists of calculated daily energy gains and theoretical storage changes corresponding to the theoretical inflow conditions. The theoretical storage changes are saved and stored in a revised master data file. The computed daily energy gains are verified by comparing monthly and yearly totals to the reported hydropower facility generation using a statistical routine. The statistical routine provides correction factors that are used to adjust the rating equations for greater simulation accuracy. To verify that the reservoir operating rules are simulating accurately, the theoretical storage with all affecting upstream reservoirs included are plotted against the actual reservoir storage. The two curves should follow the same general shape; if not, they are readjusted to produce a better simulation. After all adjustments have been made to the data requirements, the HWBEG model is then run again for all hydropower facilities being investigated for headwater benefits.

The HWBEG model was originally written in PL-1 for mainframe computers and has since been replaced by a microcomputer version. In an effort to make the HWBEG model more useful in conducting headwater benefits determinations, a number of enhancements were made to the microcomputer version of the model (FERC, 1993a). The enhancements to the microcomputer version of the HWBEG model include:

- Allow determinations to be based on the use of data collected on a monthly basis. This option would be used to make a preliminary evaluation of potential benefits derived from upstieam storage projects. Because flows are averaged over an entire month, this option is most accurate in basins subject to a high degree of flow regulation (i.e., uniform daily flow releases). The method is least accurate in basins having highly variable flows.

- $\quad$ Provide for more direct adjustment of reservoir operating rules to account for evaporative losses.

- Provide the option to include daily consumptive use lost to the system (offstream withdrawals).

- Allow the use of a power equation based on net head, flow, and plant efficiency for a turbine-generator instead of a rating equation when actual generation is unavailable.

The intent of these enhancements is to provide greater flexibility in use of the computer model and to permit use of the model in situations where data are missing or not readily available (FERC, 1993a). However, it must be recognized that FERC has put these enhancements to only minimal use, and further testing and validation is required before they can be used more extensively.

The HWBEG model is an accepted procedure having been validated according to DOE/EIA standards by ORNL and used in numerous river basin studies over the last 20 years. The model is capable of handling complex river basins with as many as 30 reservoirs including federal headwater projects. However, the robustness of the HWBEG model is not without cost. The HWBEG model is data intensive and requires considerable FERC staff time to implement in making headwater benefit determinations. It is also apparent that applying the model to non-complex basins is not costeffective (i.e., the value of the headwater benefits versus the cost of the determination). 


\subsection{FLOW DURATION ANALYSIS METHODOLOGY}

When energy gains are expected to be small and/or where basins are not complex, the flow duration analysis (FDA) method may be able to provide a good approximation of energy gains. The FDA method also requires considerably less time and effort to use than the HWBEG model. Since downstream owners are required by law to pay for the cost of conducting headwater benefits investigations, the use of an FDA method results in reduced total charges-equitable portion of the annual Section 10(f) costs plus the cost of conducting the investigation.

A flow duration curve shows the percentage of time (percent exceedance) a given flow is equaled or exceeded during a specified period of time. For any downstream site, a flow duration curve is constructed by organizing each flow recording (usually a daily flow reading) by size rather than in chronological sequence (see Fig. 2.1). The area under the flow duration curve represents the average flow for the particular period of record.

In conducting a headwater benefits investigation, flow duration curves are constructed before and after the installation of the headwater project (see Fig. 2.2). The presence of the headwater project tends to alter the pattern of streamflows by increasing the occurrence of mid-range flows and decreasing the occurrence of very high and very low flows. If there is an overall increase in the occurrence of flows within the turbine flow range, the presence of the headwater project provides downstream benefits. The flow contributing to the energy gains is represented by the difference in areas under the before and after flow duration curves bounded by the turbine flow range. If the conversion efficiency from water to power is assumed to remain constant within the turbine flow range, the difference in area between the before and after curves would be equivalent to the energy gains (see below). As shown in the example depicted in Figure 2.2, flows are above the minimum turbine flow about $80 \%$ of the time before the installation of the headwater project, and are above the maximum turbine capacity $32 \%$ of the time resulting in water spillage. Figure 2.2 also shows the flow duration curve after the installation of the headwater project. As discussed, the headwater project tends to lessen the occurrence of very high and very low flows. The after flow duration curve shows flow exceeds the minimum turbine flow $90 \%$ of the time, and is above the maximum turbine capacity only $22 \%$ of the time, resulting in less water being spilled. 
Hydrograph

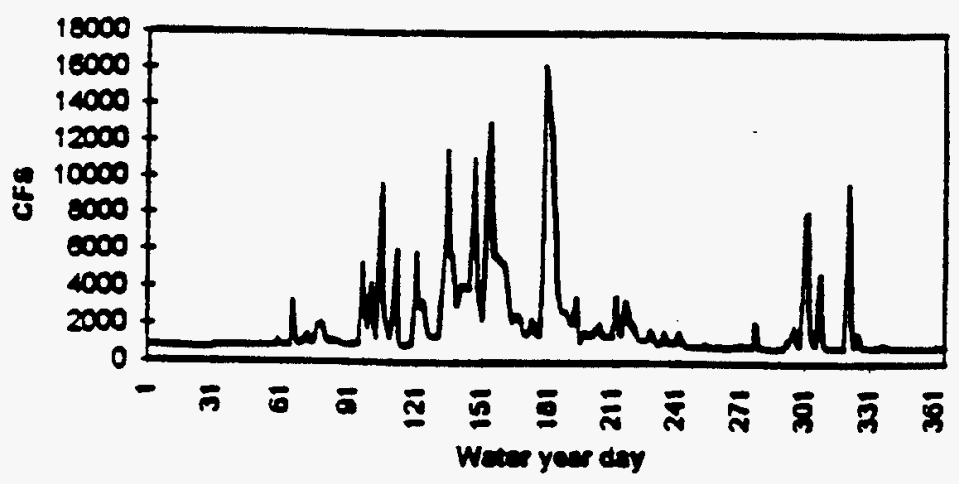

Flow duration curve

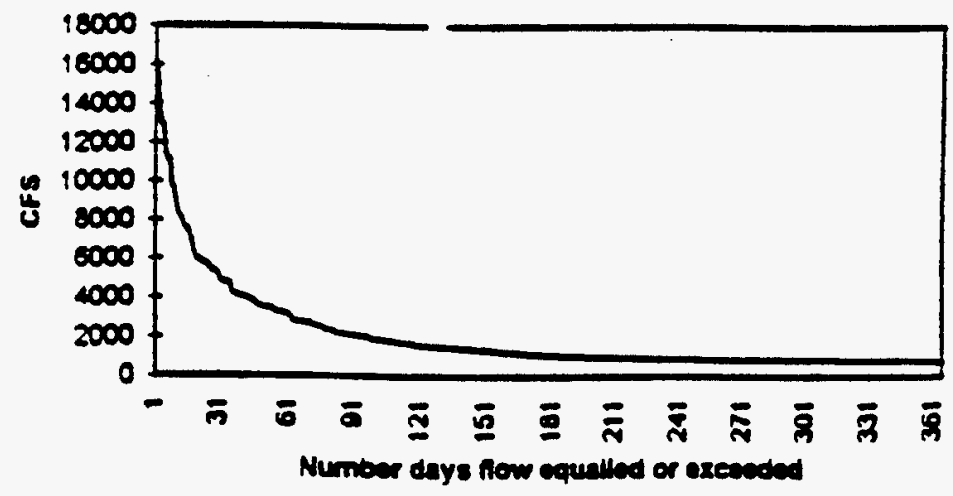

Fig. 2.1. Construction of flow duration curve from streamflow hydrograph. 


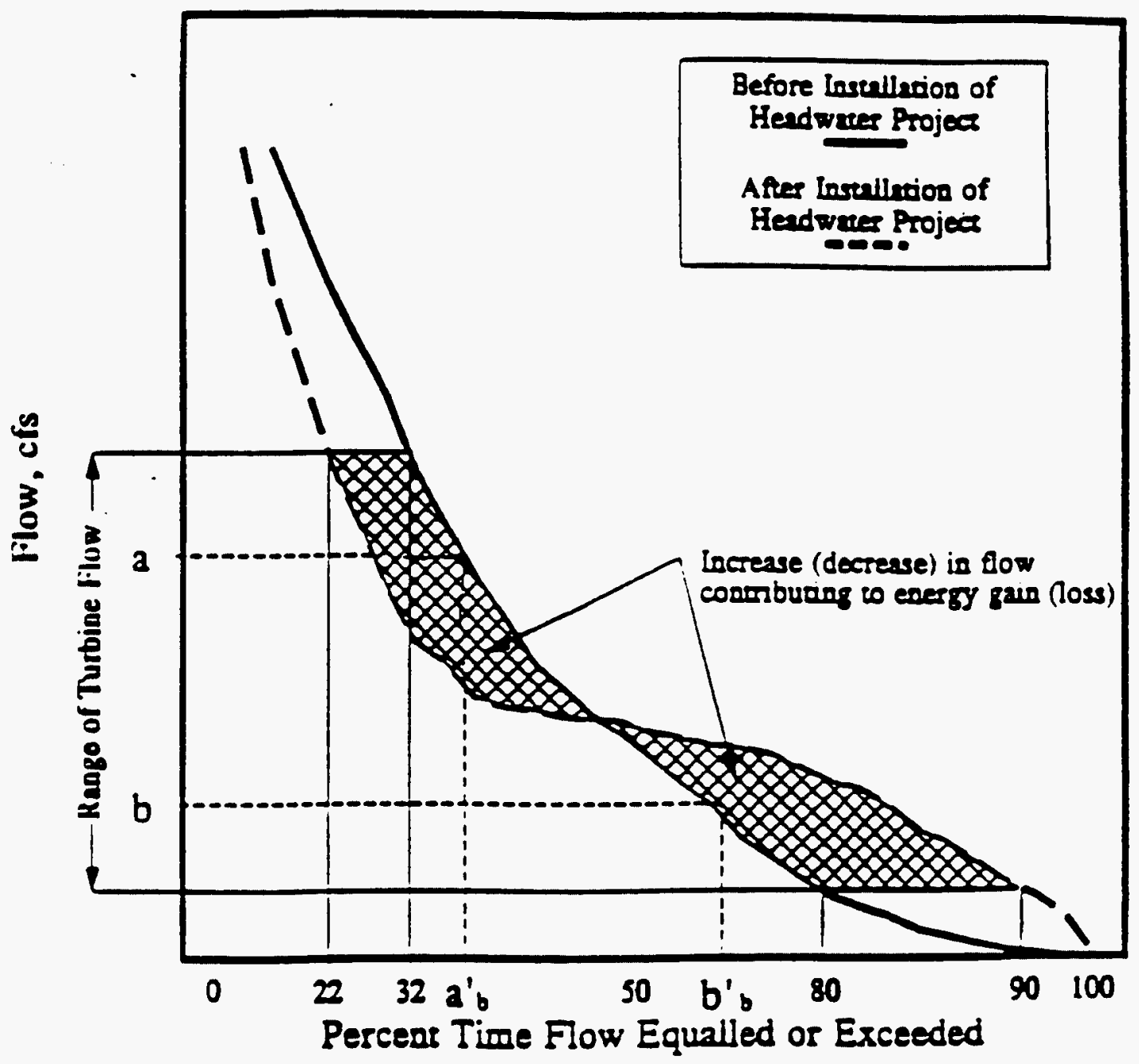

Fig. 2.2. Example of before and after flow duration curve. 
Operationally, energy gains are computed in the following sequence of steps (FERC, 1993a).

Step 1. Divide the range of flows into a series of increments over the entire range of flows between the minimum and maximum turbine flows (e.g., $50 \mathrm{cfs}$ ). ${ }^{7}$ For illustration, one incremental range is shown in Figure 2.2 as $(a-b)$.

Step 2. Determine the percent of time flow is equaled or exceeded from the flow duration curve. For the before the headwater project installation, these points are shown $a_{b}{ }^{\prime}$ and $b_{b}{ }^{\prime}$ in Figure 2.2.

Step 3. Determine the duration, which is defined as the difference in percent exceedance, computed as:

$$
d=\left[\left(b_{b}^{\prime}-a_{b}^{\prime}\right) / 100\right] \times 8760 h r s / y r
$$

Step 4. The average turbine flow (cfs) is calculated for the increment range:

$$
(a+b) / 2
$$

Step 5. The incremental flow duration is calculated as the product of the duration (hrs) in step 3 and the average turbine flow (cfs) in step 4:

$$
I F D=d \times(a+b) / 2
$$

Step 6. Calculate the energy over the entire turbine flow range. This is the product of the total incremental flow duration (summed from the minimum to the maximum turbine flow range) and a constant power to flow ratio $(\mathrm{kW} / \mathrm{cfs})$.

$$
E=\sum_{\operatorname{Min}_{c f s}}^{\operatorname{Max}_{c f s}} I F D \times(k W / c f s)
$$

These steps are repeated for both the "before" and "after" flow duration curves. Subtracting the before the headwater project installation energy generation from the after energy generation yields the gross energy gains $\left(E_{g}\right)$ for the period under consideration.

\subsubsection{Adjustments and Data Considerations}

\section{Adjustments}

The preceding steps provide FERC with an estimate of the gross energy gains $\left(E_{g}\right)$ due to the presence of the headwater project. The gross energy gains implicitly assumes that the benefitting

${ }^{7}$ More discussion on the choice of the increment size required for the numerical integration is provided later in this report. 
hydro stations are operating $100 \%$ of the time and there are no plant outages. To account for outages, whether they are scheduled or unscheduled, FERC adjusts the gross energy gains based on actual operating experience during the assessment period to arrive at net energy gains $\left(E_{n}\right)$. This is done by computing a ratio of actual average annual generation to annual generation calculated by the FDA method. The gross energy gains are then reduced by this ratio.

$$
E_{n}=E_{g} \times\left(k W h_{a c t} / k W h_{F D A}\right)
$$

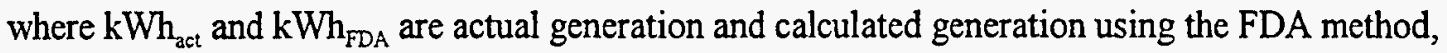
respectively.

In addition to adjusting for outages, FERC may also adjust the flow duration curves to ensure that the areas under the before and after curves are nearly equal. This is accomplished by shifting the before flow duration curve up or down depending on whether there was an increase or decrease in the volume of water. This adjustment is necessary so that a more accurate assessment of energy gains can be made.

\section{Data}

Generally, FERC requests detailed data from the federal headwater project owner and owners of the benefiting downstream hydropower facilities. These data include general descriptive information about the hydro project (name, location, capacity, year on-line, etc.); annual data on generation, outages, reservoir operating rules, and any significant events; and daily data on outflows, turbine flows, spillage, pool elevation, storage changes, etc. In addition, streamflow data (mean daily flows and minimum and maximum daily flows) are requested from the USGS to supplement the data obtained from downstream project owners. FERC attempts to acquire streamflow data from gaging stations nearest to the hydro stations benefitting from flow regulation. When gaging stations are not closely located to the hydro stations, the flow values must be adjusted by drainage basin area.

\subsubsection{Power Generation and Turbine Flow Considerations}

Power that can be generated from the kinetic energy of the falling water is functionally related to the flow (cfs), the net head on the turbines (feet), and the combined efficiency of the turbines and generators (\%). The net head is the difference between the headwater and tailwater elevations minus head losses as water moves through the penstock. The combined efficiency of the turbines and generators tends to increase from the minimum turbine flow requirements through to the design flow. Higher flows typically mean a greater overall conversion efficiency.

As discussed, FERC uses an average power-to-flow ratio for all flow ranges. Although net head and turbine-generator efficiency may vary over the range of flows, the use of this constant is considered a good approximation for determining annual energy gains provided overestimated energy gains under low flows are offset by underestimated energy gains under high flow conditions. 


\section{HWBEG MODEL COMPUTATION OF ENERGY GAINS USING DAILY AND MONTHLY DATA}

In this section, we use the HWBEG model to calculate daily and monthly energy gains at the Logan Martin and Lay hydropower projects in the Alabama River Basin and the Tulloch project in the Stanislaus River Basin. We then compare our results with energy gains determined independently by the FERC. This comparison is necessary to ensure that there are no modeling or computation errors in our use of the HWBEG model and to provide a baseline or benchmark against which the FDA method can be evaluated for accuracy. We also compare the energy gains computation on a monthly basis with energy gains calculated using daily data. This is done to determine if the monthly data option in HWBEG is a reasonable approximation to energy gains computed on a daily basis or is an acceptable alternative to the FDA method.

\subsection{MODEL BACKGROUND}

The HWBEG model uses a stepwise approach to simulate theoretical hydropower generated by unregulated streamflow by first eliminating the effects of all upstream reservoir storage. As each reservoir is added back to the system according to the first-in-time priority principle, energy generated from the regulated streamflow is calculated. The difference in power generated between the unregulated and regulated flow conditions is the energy gain. The major input data requirements for using the HWBEG model are contained in the MASTER and HWBIN data file. The MASTER data file contains observed daily flow, power generation, and storage changes. The HWBIN data file includes the sequential connection of the upstream reservoir-river network and rating equations for power-turbine flow relationships at each power plant. Subroutines for reservoir operation rules are explicitly developed for each reservoir. After data files are assembled, data are corrected and adjusted as necessary (e.g, negative inflows due to wind effects or recording error).

Two basins were chosen for this study-the Alabama and Stanislaus River Basins. These two basins are representative of the kinds of basins that have been investigated using the HWBEG model. The Alabama River Basin is a relatively complex system consisting of two headwater projects that provide flow regulation to seven downstream projects located on the Coosa River and two projects further downstream on the Alabama River (Fig. 3.1). Five of the downstream projects have storage reservoirs and provide additional flow regulation. The remaining four projects are run-of-the-river. The 1974-81 period is used to calculate energy gains for the Logan Martin and the Lay hydropower plants. The Logan Martin project has a storage reservoir and the Lay facility is operated in a run-ofthe-river mode.

In contrast to the Alabama system, the Stanislaus River Basin is simple and consists of a single flowregulating headwater project and three downstream hydropower projects. The first downstream project, Tulloch hydropower plant, operates as a run-of-the-river facility and relies on upstream flow regulation from the Bureau of Reclamation's New Melones headwater project. The other two hydropower plants are also run-of-the-river, but only generate power during the irrigation season (Fig. 3.1). Energy gains are calculated for the Tulloch facility for the 1980 to 1991 period.

As mentioned earlier, the HWBEG model has a monthly data option. The FERC developed this enhancement for preliminary investigations in basins having a high degree of flow regulation. We reviewed its use as a possible alternative to the FDA method in the non-complex basins or where the size of the headwater benefit charges would not justify the use of the HWBEG model run on a daily 


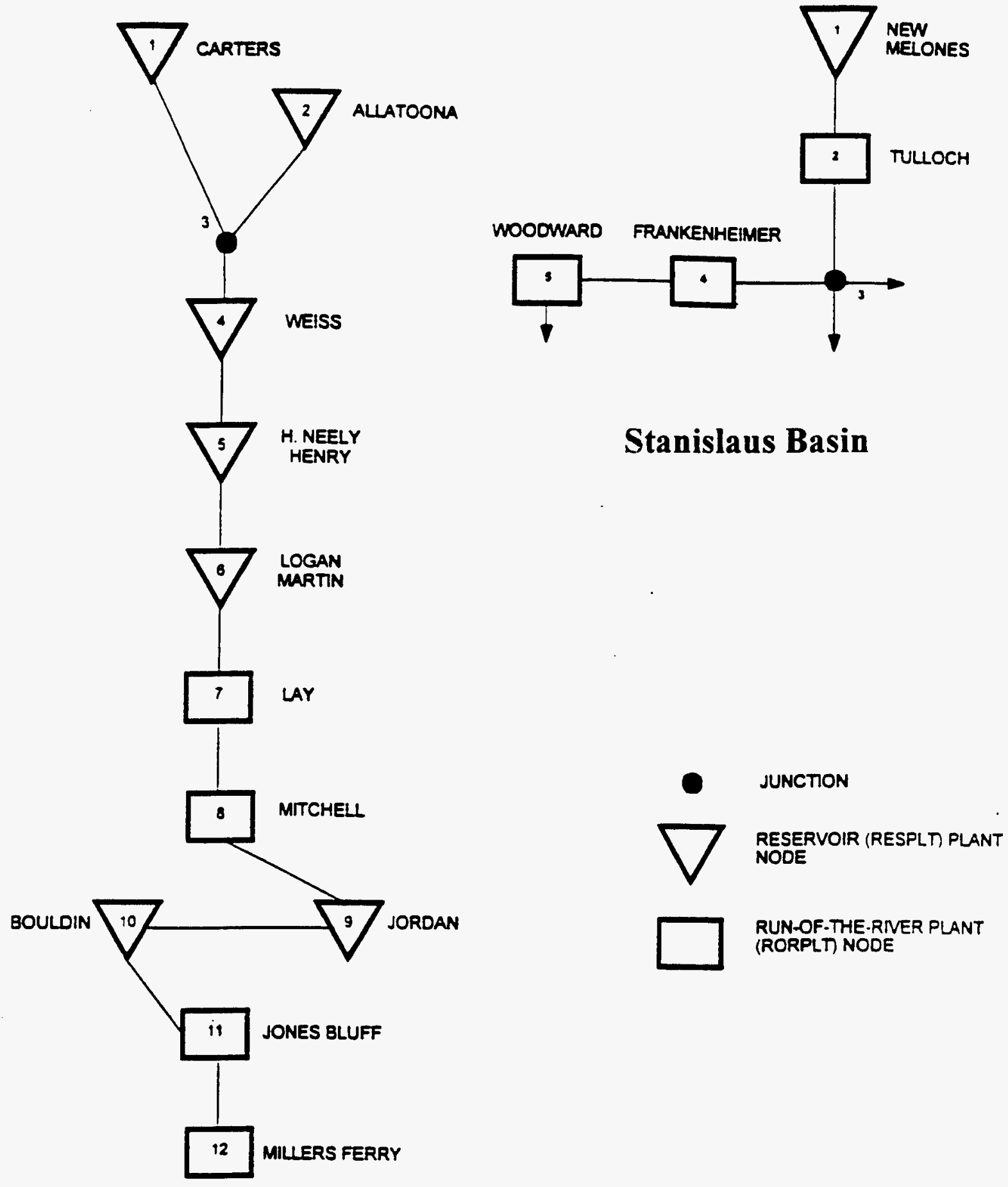

\section{Alabama Basin}

Fig. 3.1 Schematic representation of the Alabama and Stanislaus River Basins (Source: FERC 1992, 1993a). 
time-step. We also compared the daily and monthly data to determine whether the monthly data can be used for the projects where the extensive daily flow data are not available.

In the HWBEG model, the structure of the monthly MASTER data file and the daily MASTER data file are identical. The only difference is that the values of daily data entries in the monthly MASTER data file are fixed for each month. We developed a computer code (DAILYIN.FOR) to create the monthly MASTER data file by averaging flow, power generation, and storage changes from the daily data files. Our algorithm is similar to the MON.FOR subroutine in HWBEG model. However, monthly averaged flow, power, and storage changes are known in MON.FOR.

\subsection{COMPARATIVE RESULTS}

In Table 3.1, we report yearly totals of daily energy gains for the Lay hydropower project due to the regulated flow from the Allatoona and Carters headwater projects, and for the Tulloch hydropower plant from the New Melones-regulated flow. For the Alabama River Basin, the daily energy gains that we calculated using HWBEG are identical to those reported by the FERC for the same period. Energy gains for the Logan Martin facility, which are not shown in Table 3.1, are also identical to the values reported by the FERC. For the Stanislaus Basin, our HWBEG-calculated energy gains are nearly identical to those reported by the FER.C (FERC, 1992). The slight percent differences are basically a result of numerical roundoff error in summation of annual energy gains (FERC, 1992). The large percent difference shown for 1983 is due to the small size of the energy gain and is within the absolute difference range for other years.

\subsubsection{Daily and Monthly Energy Gains Comparisons}

Annual energy gains computed at the Logan Martin, Lay, and Tulloch hydropower plants are summarized for all upstream reservoirs for both daily and monthly time steps in Tables 3.2-3.4, respectively. Power generation under theoretical unregulated flow conditions and observed annual power generation at the power plants are also listed in the summary tables. For the two projects in the Alabama River Basin, inonthly values (summed for both the Allatoona and Carters headwater projects) show a $50 \%$ to $60 \%$ reduction in energy gains at the Logan Martin and Lay hydropower plants. For the Tulloch hydropower plant in the Stanislaus River Basin, the net difference between energy gains computed daily and monthly over the 13 -year period is only $3.5 \%$. However, the percent differences on a yearly basis range from nearly $2000 \%$ in 1980 to $-663 \%$ in 1981 (energy loss).

The annual variation in energy gains differences between the daily and monthly calculation options are much smaller in the Alabama River Basin than in the Stanislaus River Basin. The smaller difference is because the Alabama Basin is a relatively complex river system with many storage reservoirs re-regulating flows from the two headwater projects (Allatoona and Carters). The Stanislaus River Basin is a simple system with only one upstream reservoir. The multiple upstream reservoirs in a complex river-reservoir system, such as the Alabama, tend to "smooth" the flow discharge pattern at downstream hydropower sites. This smoothing lessens the variation in the difference in energy gains calculated on a daily and monthly time step. 
Table 3.1 Summary comparison of energy gains for the Alabama River Basin (Lay hydropower project) and the Stanislaus River Basin

(Tulloch hydropower project).

(a) Alabama River Basin

Annual Energy Gains at Lay Hydropower Project

\begin{tabular}{l|c||c|c|c}
\hline \multirow{2}{*}{ Year } & \multicolumn{4}{|c}{$\begin{array}{c}\text { Annual energy gains } \\
\text { (MWh) }\end{array}$} \\
\cline { 2 - 5 } & \multicolumn{3}{|c|}{ Allatoona } & Carter \\
\cline { 2 - 5 } & ORNL & Reported & ORNL & Reported \\
\hline 1974 & 17058.1 & 17058.1 & -1488.8 & -1488.8 \\
1975 & 19949.3 & 19949.3 & -13156.1 & -13156.1 \\
1976 & 27001.7 & 27001.7 & 1087.1 & 1087.1 \\
1977 & 38217.5 & 38217.5 & 7426.5 & 7426.5 \\
1978 & 12446.2 & 12446.2 & 1265.4 & 1265.4 \\
1979 & 32623.3 & 32623.3 & 5121.9 & 5121.9 \\
1980 & 25173 & 25173 & 3367.6 & 3367.6 \\
1981 & 9367.9 & 9367.9 & 228.2 & 228.2 \\
1982 & 21441.6 & 21441.6 & 4386.2 & 4386.2 \\
\hline
\end{tabular}

(b) Stanislaus River Basion

Annual Energy Gains at Tulloch Hydropower Project

\begin{tabular}{c|c|c|c}
\hline \multirow{4}{*}{ Year } & \multicolumn{4}{|c}{ Annual Energy Gains at Tulloch Hydropower Project } \\
\cline { 2 - 4 } & ORNL & Reported & $\begin{array}{c}\text { Difference } \\
(\%)\end{array}$ \\
\hline 1979 & 11193.5 & 11184.3 & $0.08 \%$ \\
1980 & 191.6 & 194.3 & $-1.39 \%$ \\
1981 & 1149.3 & 1150.4 & $-0.10 \%$ \\
1982 & -8478 & -8460.7 & $0.20 \%$ \\
1983 & -77.9 & -62 & $25.65 \%$ \\
1984 & 13656.5 & 13650.8 & $0.04 \%$ \\
1985 & 17095.7 & 17083.9 & $0.07 \%$ \\
1986 & 16760.8 & 16765.8 & $-0.03 \%$ \\
1987 & 47152.4 & 47136.1 & $0.03 \%$ \\
1988 & 47516.6 & 47505.9 & $0.02 \%$ \\
1989 & 5219.5 & 5218.7 & $0.02 \%$ \\
1990 & 33298.7 & 33289.9 & $0.03 \%$ \\
1991 & 4250.6 & 4248.9 & $0.04 \%$ \\
\hline
\end{tabular}


Table 3.2 Comparison of daily and monthly energy gains calculations for the Logan Martin hydropower project in the Alabama River Basin (1974-1982).

(a) Calculated from daily data (MWh)

\begin{tabular}{|c|c|c|c|c|c|c|c|c|c|c|c|c|}
\hline \multirow[b]{2}{*}{ Year } & \multirow{2}{*}{$\begin{array}{l}\text { Reported } \\
\text { |Energy }\end{array}$} & \multirow[b]{2}{*}{ Energy w/o } & \multicolumn{2}{|c|}{ Allatoona } & \multicolumn{2}{|c|}{ Weiss } & \multicolumn{2}{|c|}{ Henry } & \multicolumn{2}{|c|}{ Carters } & \multirow[b]{2}{*}{ Total gain } & \multirow{2}{*}{$\begin{array}{l}\text { \%difference btw } \\
\text { daily and monthly }\end{array}$} \\
\hline & & & Energy & Energy gain & Energy & Energy gain & Energy & Energy gain & Energy & Energy gain & & \\
\hline 1974 & 430373 & 409180 & 418475.6 & 9295.6 & 431135.6 & 12660 & 431406.1 & 270.4 & 30371.9 & -1034.2 & 21191.8 & -74.70 \\
\hline 1975 & 532600 & 517570.7 & 530547.5 & 12976.8 & 542370.7 & 11823.1 & 542782 & 411.3 & 532610.1 & -10171.9 & 15039.3 & -64.91 \\
\hline 1976 & 436398 & 408845.1 & 428753.3 & 19908.3 & 434031.9 & 5278.5 & 435195.4 & 1163.6 & 436423.7 & 1228.2 & 27578.6 & -59.41 \\
\hline 1977 & 452561 & 411424.3 & 433412.6 & 21988.3 & 445811.1 & 12398.6 & 447018.9 & 1207.8 & 452561.7 & 5542.7 & 41137.4 & -58.49 \\
\hline 1978 & 321730 & 305538.4 & 313115.9 & 7577.5 & 320962.8 & 7846.9 & 321190.7 & 227.9 & 321424.7 & 234 & 15886.3 & -90.97 \\
\hline 1979 & 529901 & 490809.7 & 513781.4 & 22971.7 & 523506.3 & 9725 & 526971.6 & 3465.2 & 529961.2 & 2989.7 & 39151.6 & -55.85 \\
\hline 1980 & 455485 & 424394.3 & 441563.1 & 17168.8 & 450824.3 & 9261.2 & 452197.5 & 1373.2 & 454836.8 & 2639.3 & 30442.5 & -28.25 \\
\hline 1981 & 247134 & 236650.4 & 243017.4 & 6367 & 246312.8 & 3295.4 & 246728 & 415.2 & 247057.6 & 329.7 & 10407.3 & -101.19 \\
\hline 1982 & 501800 & 465646 & 477095.6 & 11449.6 & 497696.3 & 20600.7 & 499226.5 & 1530.1 & 501784.2 & 2557.7 & 36138.1 & -84.75 \\
\hline
\end{tabular}

(b) Calculated from monthly data (MWh)

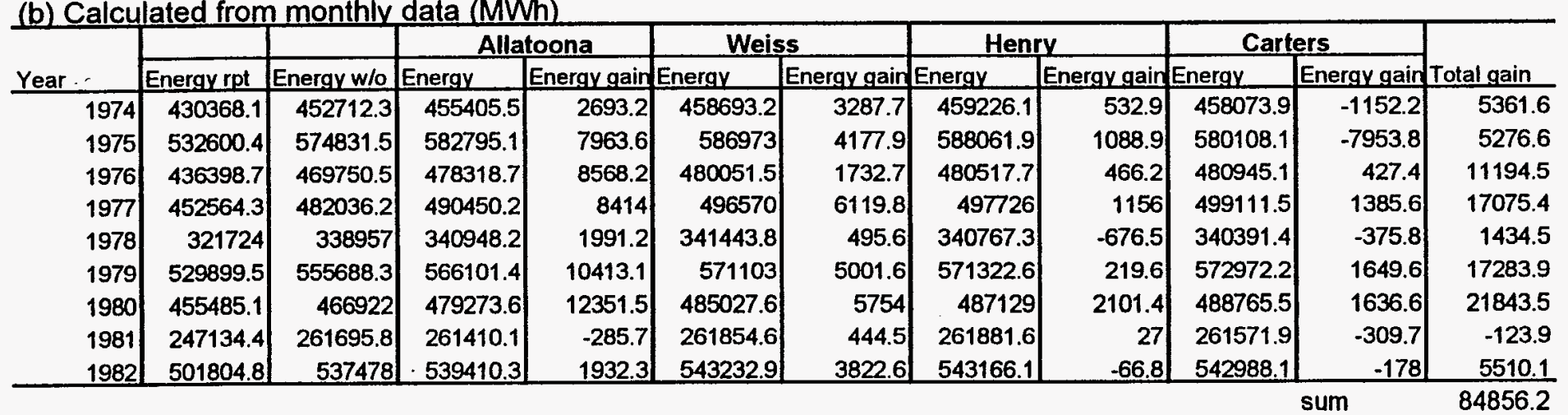


Table 3.3 Comparison of daily and monthly energy gains calculations for the Lay hydropower project in the Alabama River Basin (1974-1982).

(a) Calculated from daily data (MWh)

\begin{tabular}{|c|c|c|c|c|c|c|c|c|c|c|c|c|c|c|}
\hline \multirow[b]{2}{*}{ Year } & \multirow{2}{*}{$\begin{array}{l}\text { Reported } \\
\text { Energy }\end{array}$} & \multirow[b]{2}{*}{ Energy w/ } & \multicolumn{2}{|c|}{ Allatoona } & \multicolumn{2}{|c|}{ Weiss } & \multicolumn{2}{|c|}{ Martin } & \multicolumn{2}{|c|}{ Henry } & \multicolumn{2}{|c|}{ Carters } & \multirow[b]{2}{*}{ Total gain } & \multirow{2}{*}{$\begin{array}{l}\text { \%difference btw } \\
\text { daily and month! }\end{array}$} \\
\hline & & & Energy & Energy gai & Energy & Energy gai & Energy & Energy gai & Energy & Energy gai & Energy & Energy gai & & \\
\hline 1974 & 668571 & 633128.9 & 650187 & 17058.1 & 668065 & 17878.3 & 669496 & 1430.8 & 670058 & 562.1 & 668569 & -1488.8 & 35440.5 & -52.61 \\
\hline 1975 & 842193 & 814831.4 & 834781 & 19949.3 & 853716 & 18935 & 855289 & 1572.8 & 855349 & 60.7 & 842193 & -13156.1 & 27361.7 & -54.85 \\
\hline 1976 & 666407 & 625503.5 & 652505 & 27001.7 & 660068 & 7562.9 & 663068 & 2999.9 & 665364 & 2296.1 & 666451 & 1087.1 & 40947.7 & -45.36 \\
\hline 1977 & 705104 & 635536.6 & 673754 & 38217.5 & 693646 & 19892.3 & 695791 & 2144.3 & 697678 & 1887.7 & 705105 & 7426.5 & 69568.3 & -54.90 \\
\hline 1978 & 522450 & 494620.7 & 507067 & 12446.2 & 517829 & 10762 & 519755 & 1926.1 & 520740 & 984.7 & 522005 & 1265.4 & 27384.4 & -66.88 \\
\hline 1979 & 822528 & 760304.8 & 792928 & 32623.3 & 807044 & 14115.4 & 812560 & 5516.5 & 817391 & 4830.8 & 822513 & 5121.9 & 62207.9 & .45 .25 \\
\hline 1980 & 694881 & 649327.9 & 674501 & 25173 & 685949 & 11447.8 & 688463 & 2514.4 & 691739 & 3276.1 & 695107 & 3367.6 & 45778.9 & -22.01 \\
\hline 1981 & 400544 & 388483.8 & 397852 & 9367.9 & 400506 & 2654.1 & 399620 & -886.1 & 400264 & 644.5 & 400493 & 228.2 & 12008.6 & -84.48 \\
\hline 1982 & 778544 & 715905.2 & 737347 & 21441.6 & 769327 & 31980.3 & 770298 & 970.4 & 774156 & 3858.3 & 778542 & 4386.2 & 62636.8 & -65.09 \\
\hline
\end{tabular}

(b) Calculated from monthly data (MWh)

\begin{tabular}{|c|c|c|c|c|c|c|c|c|c|c|c|c|c|}
\hline \multirow[b]{2}{*}{ Year } & \multirow{2}{*}{\begin{tabular}{|l|} 
Reported \\
Energy \\
\end{tabular}} & \multirow[b]{2}{*}{ Energy w/ } & \multicolumn{2}{|c|}{ Allatoona } & \multicolumn{2}{|c|}{ Weiss } & \multicolumn{2}{|c|}{ Martin } & \multicolumn{2}{|c|}{ Henry } & \multicolumn{2}{|c|}{ Carters } & \multirow[b]{2}{*}{ Total gain } \\
\hline & & & Energy & Energy gai & Energy & Energy gai & Energy & Energy gai & Energy & Energy gai & Energy & Energy gai & \\
\hline 1974 & 668573 & 700086.4 & 706761 & 6674.6 & 715082 & 8321.3 & 717671 & 2588.8 & 718540 & 869.3 & 716881 & -1659.4 & 16794.6 \\
\hline 1975 & 842191 & 916632 & 928851 & 12219.1 & 934029 & 5178 & 934527 & 498.1 & 936467 & 1940 & 928986 & -7480.8 & 2354.4 \\
\hline 1976 & 666409 & 729226.1 & 745854 & 16627.7 & 750345 & 4491.7 & 750703 & 357.5 & 750973 & 269.8 & 751600 & 627 & 22373.7 \\
\hline 1977 & 705105 & 734422.2 & 746676 & 12253.9 & 753865 & 7188.8 & 761411 & 7545.8 & 763992 & 2581.1 & 765797 & 1804.8 & 31374.4 \\
\hline 1978 & 522451 & 547055 & 552617 & 5562.4 & 555701 & 3083.1 & 556659 & 958.4 & 556362 & -297.3 & 556123 & -238 & 9068.6 \\
\hline 1979 & 822527 & 867485.3 & 879234 & 11749 & 886455 & 7220.9 & 897132 & 10676.9 & 900060 & 2928 & 901543 & 1483 & 34057.8 \\
\hline 1980 & 694887 & 714663.5 & 732084 & 17420 & 739255 & 7171.2 & 743631 & 4375.8 & 747798 & 4167 & 750365 & 2567.8 & 35701.8 \\
\hline 1981 & 400543 & 435272.6 & 435368 & 95.5 & 435642 & 274.1 & 437394 & 1751.3 & 437665 & 271 & 437137 & -527.9 & 1864 \\
\hline 1982 & 778546 & 825636.9 & 836236 & 10599.4 & 846852 & 10616 & 847400 & 547.3 & 847446 & 46.1 & 847504 & 58.6 & 21867.4 \\
\hline
\end{tabular}


Table 3.4 Comparison of daily and monthly energy gains calculations for the Tulloch hydropower project in the Stanislaus River Basin (1979-1991).

(a) Energy gains calculated from daily data (MWh)

\begin{tabular}{|c|c|c|c|c|c|}
\hline \multirow[b]{2}{*}{ Year } & \multirow{2}{*}{$\begin{array}{c}\text { Reported } \\
\text { Energy }\end{array}$} & \multirow[b]{2}{*}{ Energy w/o } & \multicolumn{2}{|c|}{ New Melones } & \multirow{2}{*}{$\begin{array}{c}\% \text { difference between } \\
\text { daily and monthly }\end{array}$} \\
\hline & & & Energy & Energy gain & \\
\hline 1979 & 43623 & 32091.4 & 43284.9 & 11193.5 & 14.82 \\
\hline 1980 & 109197 & 108220.5 & 108412.1 & 191.6 & 1999.58 \\
\hline 1981 & 81767 & 80170.9 & 81320.2 & 1149.3 & -662.69 \\
\hline 1982 & 118365 & 126579.6 & 118101.6 & -8478 & 23.64 \\
\hline 1983 & 127748 & 128505.7 & 128427.9 & -77.9 & 454.81 \\
\hline 1984 & 128118 & 113372.6 & 127029.1 & 13656.5 & -11.28 \\
\hline 1985 & 101045 & 84251.1 & 101346.8 & 17095.7 & -9.04 \\
\hline 1986 & 115500 & 98793.1 & 115553.9 & 16760.8 & 8.04 \\
\hline 1987 & 90760 & 43543.1 & 90695.4 & 47152.4 & 7.93 \\
\hline 1988 & 91313 & 43631.1 & 91147.8 & 47516.6 & 12.94 \\
\hline 1989 & 86371 & 80944.2 & 86163.7 & 5219.5 & -52.18 \\
\hline 1990 & 87927 & 55077.1 & 88375.8 & 33298.7 & 16.25 \\
\hline 1991 & 71346 & 67598.8 & 71849.4 & 4250.6 & 8.00 \\
\hline & & & Sum & 188929.3 & 3.54 \\
\hline
\end{tabular}

(b) Energy gains calculated from monthly data (MWh)

\begin{tabular}{|c|c|c|c|c|}
\hline \multirow[b]{2}{*}{ Year } & \multirow{2}{*}{$\begin{array}{l}\text { Reported } \\
\text { Energy }\end{array}$} & \multirow[b]{2}{*}{ Energy w/o } & \multicolumn{2}{|c|}{ New Melones } \\
\hline & & & Energy & Energy gain \\
\hline 1979 & 43623.2 & 31214.4 & 44066.9 & 12852.4 \\
\hline 1980 & 109197 & 111376.2 & 115399 & 4022.8 \\
\hline 1981 & 81766.8 & 90412.5 & 83945.5 & -6467 \\
\hline 1982 & 118364.5 & 131735.3 & 121253 & -10482.3 \\
\hline 1983 & 127747.8 & 130639 & 130206.8 & -432.2 \\
\hline 1984 & 128117.9 & 115664.5 & 127781 & 12116.6 \\
\hline 1985 & 101045.4 & 87065 & 102615.1 & 15550.2 \\
\hline 1986 & 115500.2 & 101330.2 & 119438 & 18107.8 \\
\hline 1987 & 90760.1 & 41691.3 & 92582.5 & 50891.2 \\
\hline 1988 & 91313 & 41099.1 & 94763.7 & 53664.6 \\
\hline 1989 & 86371 & 84571.7 & 87067.7 & 2496 \\
\hline 1990 & 87926.3 & 53061.9 & 91772.1 & 38710.2 \\
\hline 1991 & 71345.3 & 68201 & 72791.6 & 4590.6 \\
\hline
\end{tabular}


Smaller energy gains in the Alabama Basin using monthly data can also be explained for another reason. Power generation requires inflows to be within turbine flow capacity range. Within the flowturbine range is a sub-range in which the turbine and generators operate at the maximum efficiency. The process of averaging the daily inflows to develop monthly data tends to increase the low flows and reduce the extreme high flows resulting in flow patterns more favorable to power generation. Therefore, energy gains calculated using the monthly flow data will be smaller relative to those calculated using daily data because part of the function of water storage at upstream storage reservoirs is artificially imbedded in the monthly flow data set used for deriving the unregulated flows.

\subsection{CONCLUSIONS}

The following general conclusions can be made about the HWBEG model results and the comparisons between daily and monthly data.

- Application of HWBEG model to the Alabama and Stanislaus River Basins confirmed the results reported in previous published headwater benefit determinations.

- Daily data should be used, if available, instead of monthly data. Generally, the use of monthly data results in lower energy gains. This is due to the "smoothing" effect of monthly flow data.

- The difference in river-reservoir system category (complex as in the Alabama Basin and simple as in the Stanislaus Basin) will affect the computation of energy gains.

- Negative inflows, which have to be "corrected" in the data sets, can affect the difference in energy gains between those estimated daily and monthly.

- Nonlinearity of power-flow (rating curve) and reservoir operation rules also affect the difference in energy gains calculated using two data sets. 


\section{DOCUMENTATION AND ENHANCEMENTS TO THE FDA METHOD}

In this section, we briefly describe the FDA method and use it to reproduce energy gains determined and reported independently by the FERC for the James River Basin. This is done to verify that we are interpreting and using the FDA method similarly to the FERC. We then discuss the development of an enhanced FDA method. Our enhanced FDA method is more automated and easier to use. Imbedded within the enhanced version of the FDA method are options that allow one to change the flow step increment (i.e., size of daily flow classes) and to use a variable flow-head-efficiency relationship. We report on how changes in the selection of flow step size and use of a variable flowhead-efficiency relationship affect energy gains calculations. We also discuss how the length of data record can affect energy gains calculations. Both the standard and enhanced version of the FDA method is used in Section 5 for comparing FDA and HWBEG calculated energy gains.

\subsection{VERIFICATION OF THE FDA CALCULATED ENERGY GAINS}

Flow duration analysis is an established, straightforward, and accepted method for investigating numerous water-resource engineering problems (Vogel and Fennessey, 1995). A flow duration curve is developed by organizing all daily flows into groups or size classes. Beginning at the highest discharge group, the number of days when the lowest range value was exceeded is accumulated for successive classes and expressed as a percentage of the total number of days in the given period of record (FERC, 1993b). The impact from flow regulation of the headwater improvement is determined by comparing flow duration curves before and after operation of the headwater project. The flow contributing to energy gains is represented by the difference in areas under the before and after flow duration curves bounded by the turbine flow range.

We selected the Cushaw hydropower plant in the James River Basin to verify our use of the FDA method and to ensure that our results are consistent with those of the FERC. A flow data record from USGS gage station No. 02025500 at Holcomb Rock, located downstream of Cushaw hydropower plant, was obtained for water years 1928-82 and 1983-91 representing the period before and after installation of the upstream headwater Gathright Dam/Lake Moomaw project. Before computing energy gains and comparing these with gains reported by FERC in their James River report (FERC 1993b), we adjusted the flow data by drainage area ratio to correspond to the Cushaw hydropower project. As summarized in Table 4.1, a comparison of our use of the FDA method with FERC's reported results shows less than $1 \%$ difference in energy generation before and after the installation of the headwater project. However, there is a $25 \%$ or nearly $200 \mathrm{MWh}$ difference in energy gains. The reasons for this difference are discussed in the next subsection.

\subsection{DEVELOPMENT OF ENHANCED FDA METHOD}

We developed an enhanced FDA method to investigate the factors which affect energy gain calculations in general, and to explain the difference in energy gains calculated by ORNL and reported by FERC for the James River. 
Table 4.1. Comparison of annual energy gains for Cushaw Hydro Station in James River Basin, VA.

\begin{tabular}{l|c|c|c}
\hline \multicolumn{1}{c|}{ Energy } & ORNL & Reported & difference(\%) \\
\hline $\begin{array}{l}\text { Energy generation before } \\
\text { installation of headwater projects } \\
\text { (MWh) }\end{array}$ & 32669 & 32839 & -0.52 \\
$\begin{array}{l}\text { Energy generation before } \\
\text { installation of headwater projects } \\
(\mathrm{MWh})\end{array}$ & 33625 & 33603 & 0.07 \\
Annual energy gains (MWh) & 956 & 764 & 25.13 \\
\hline
\end{tabular}

The ORNL enhanced version of the FDA method, Headwater Benefits Flow Duration Analysis (HWBFDA) model, (Appendix A) consists of subroutines for inputting of daily flow data, sorting flow data to calculate flow duration curves, and calculating energy generation to estimate gains, and functions for calculation of exceedance probabilities and interpolation. We also embedded a number of options in the HWBFDA model. These options include:

- variable flow step for the numerical integration to assure that the calculation error is small and acceptable,

- minimum turbine flow capacity,

- maximum turbine flow capacity,

- efficiency of turbine power generation, and

- net hydraulic head for power generation.

In addition to evaluating how use of the above options can affect energy gains, we also evaluated how length of data record and quality of data (zero and negative flows) affect energy gains.

Finally, we added an option to the FDA method to derive unregulated flow data. This is useful when there are few flow data available before installation of upstream reservoirs. Specifically, the FDA method was modified to derive the unregulated stream flow from the regulated flow data by adding back the storage changes as indicated in the following equation:

$$
Q_{\text {in }}=Q_{\text {out }}+\Delta_{s} / \Delta_{t}
$$

where

$\mathrm{Q}_{\mathrm{in}}=$ inflow at the hydropower plant,

$\mathrm{Q}_{\text {out }}=$ outflow at the hydropower plant, and

$\Delta_{\mathrm{s}} / \Delta_{\mathrm{t}}=$ change of upstream reservoir storage.

For a multiple reservoir river system, the unregulated flow is derived by backward calculation of inflow for each reservoir sequentially to eliminate the storage effects of all upstream reservoirs. 


\subsubsection{Effects of Simulated Unregulated Flows}

We used the option for simulation of unregulated flow in the enhanced FDA model to calculate energy gains at Tulloch hydropower plant in Stanislaus River Basin. With observed flow data at Tulloch for the 1979-91 period, we simulated the unregulated flows for the same period. However, there are 198 uegative inflow data points derived for unregulated daily flow. This represents about $4.5 \%$ of the total data points. The presence of the negative inflows is difficult to explain. Possible reasons for their presence include:

- evaporation (water surface evaporation loss at the reservoir can be significant which is not considered in the above equation),

- groundwater (the above equation does not consider the interaction between the surface water and groundwater and flow gain from groundwater discharge or loss from groundwater recharge),

- wind effects at upstream reservoirs, and

- $\quad$ errors in flow and water storage measurements.

Two approaches were taken to correct the negative inflows at Tulloch: (1) excluding the negative unregulated inflow data points and (2) replacing the negative inflow data points with zero. In the first approach, removal of the negative inflows shifts the flow duration curve upward for unregulated flow. This shift reduces the energy gains (Table 4.2). In the second approach, replacing the negative inflows with zeros, which are lower than the minimum turbine flow capacity, will shift the FDA curve downward and increase the energy gains. The negative inflows may artificially increase other non-negative inflows derived. However, the same storage change, which results in negative unregulated flow, will have a similar effect on regulated flow. Therefore, the energy gains calculated in the second approach may be higher due to the zero flows in deriving the unregulated inflow data. The removal of negative inflows derived as unregulated instream flow results in a $17.8 \%$ reduction in calculated gains. Replacing the negative inflows with zeros increases energy gains by $11 \%$.

\subsection{RESULTS AND ANALYSES USING ENHANCED FDA METHOD}

\subsubsection{Effects of Flow Step Increment}

The flow step is the incremental flow used for the numerical integration in the energy equation. Figure 4.1 shows the results of 50 runs of the HWBFDA model for variable flow steps ranging from 5 to $250 \mathrm{cfs}$. As shown in Figure 4.1, the calculated energy gains tend to fluctuate as flow step increases; that is, calculated energy gains diverge at higher flow steps. To minimize numerical error, it can be inferred that the flow step should be less than $50 \mathrm{cfs}$ to limit the differences in calculated energy gains within $1 \%$ for this particular FDA case study review. The change of the incremental flow step from 5 to $250 \mathrm{cfs}$ can affect energy gains by approximately $8 \%$ (Figure 4.1 ). The impact of flow step increment on power generation is illustrated in Figure 4.2 . It can be concluded that a small flow step, say $5 \mathrm{cfs}$, should be used to minimize numerical error. 
Table 4.2 Effects of simulated unregulated flows on assessment of energy gains for Tulloch Power Plant

\begin{tabular}{|c|c|c|c|}
\hline \multirow{2}{*}{ Energy } & \multicolumn{2}{|c|}{ Simulated unregulated flows } & \multirow{2}{*}{$\begin{array}{c}\text { Observed } \\
\text { unregulated flow } \\
\text { data }\end{array}$} \\
\hline & $\begin{array}{c}\text { Exclude negative } \\
\text { inflows }\end{array}$ & $\begin{array}{c}\text { Reset negative inflows } \\
\text { as zeros }\end{array}$ & \\
\hline $\begin{array}{l}\text { Energy generation without } \\
\text { upstream reservoirs (MWh) }\end{array}$ & 94289.54 & 90202.55 & 91767.01 \\
\hline $\begin{array}{l}\text { Energy generation with upstream } \\
\text { reservoirs (MWh) }\end{array}$ & 105946.60 & 105946.60 & 105946.60 \\
\hline Energy gain (MWh) & 11657.04 & 15744.03 & 14179.57 \\
\hline $\begin{array}{l}\text { Number of negative unregulated } \\
\text { flows simulated (day) }\end{array}$ & 198 & 198 & \\
\hline Percentage of negative flow $(\%)$ & 4.53 & 4.53 & \\
\hline
\end{tabular}

\subsubsection{Effects of Length of Data Record}

Figs. 4.3-4.4 show how the length of flow data records can affect energy gains calculations. There is a $35 \%$ difference in calculated energy gains between the use of water year versus calendar year data. The main reason for the difference is that there were very low flow discharges ( $-650 \mathrm{cfs})$ during a two-month period in 1991 (October-November). These low flow data points shift the calendar year flow duration curve for flows after the installation of headwater projects downward. The following observations are made from this comparison:

- low flow data points have a considerable effect on energy gains calculations using the FDA method;

- $\quad$ effects are much less significant if more data points are available;

- daily flow data are not statistically independent (required for frequency analysis), and because the exceedance probability is calculated by plotting the position equation, the use of monthly data will not solve the problem of the low flow impact; and

- the extreme high flow data points will not affect energy gains because high flow data points may alter the flow duration curve locally (at the high flow end) and not shift the entire curve, and the higher flows generally exceed the turbine flow capacity. 


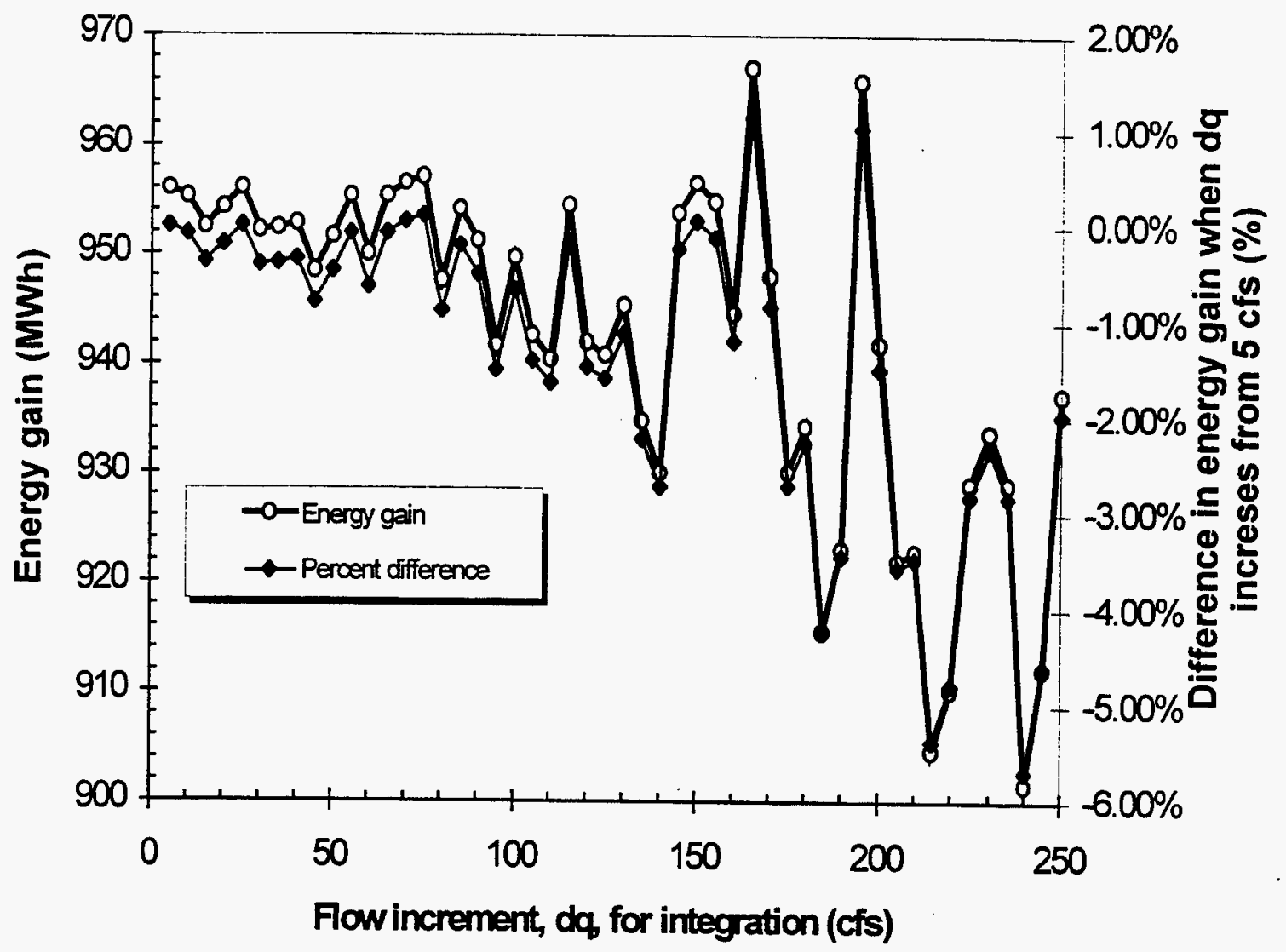

Fig. 4.1. Impact of flow increment on calculation of energy gains for Cushaw Hydropower Plant in the James River Basin based on water year data points. 


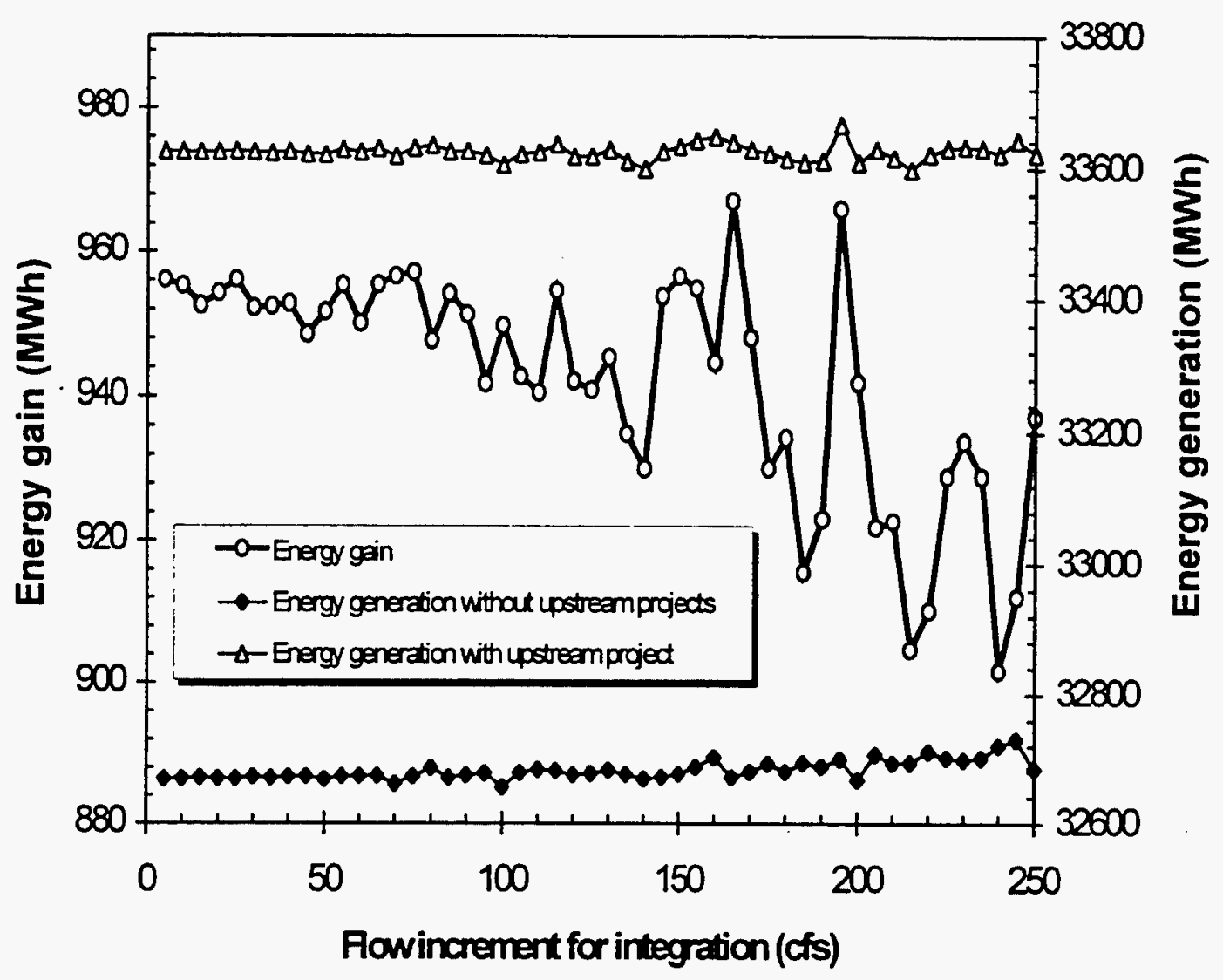

Fig. 4.2. Impact of flow increment on calculation of energy gains for Cushaw Hydropower Plant in the James River Basin based on water year data points. 


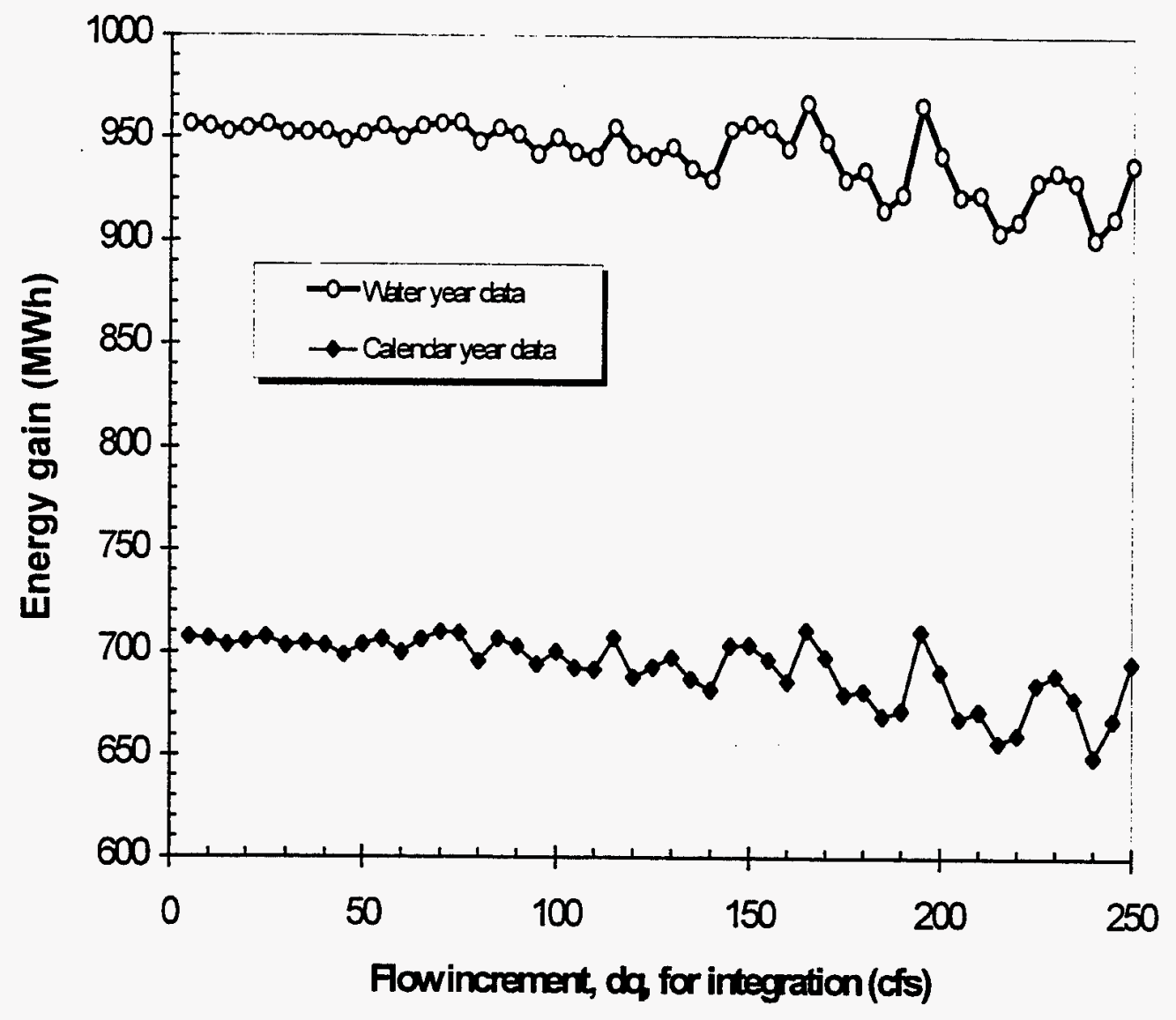

Fig. 4.3. Comparison of energy gains using water-year and calendar-year data for Cushaw Hydropower Plant. 


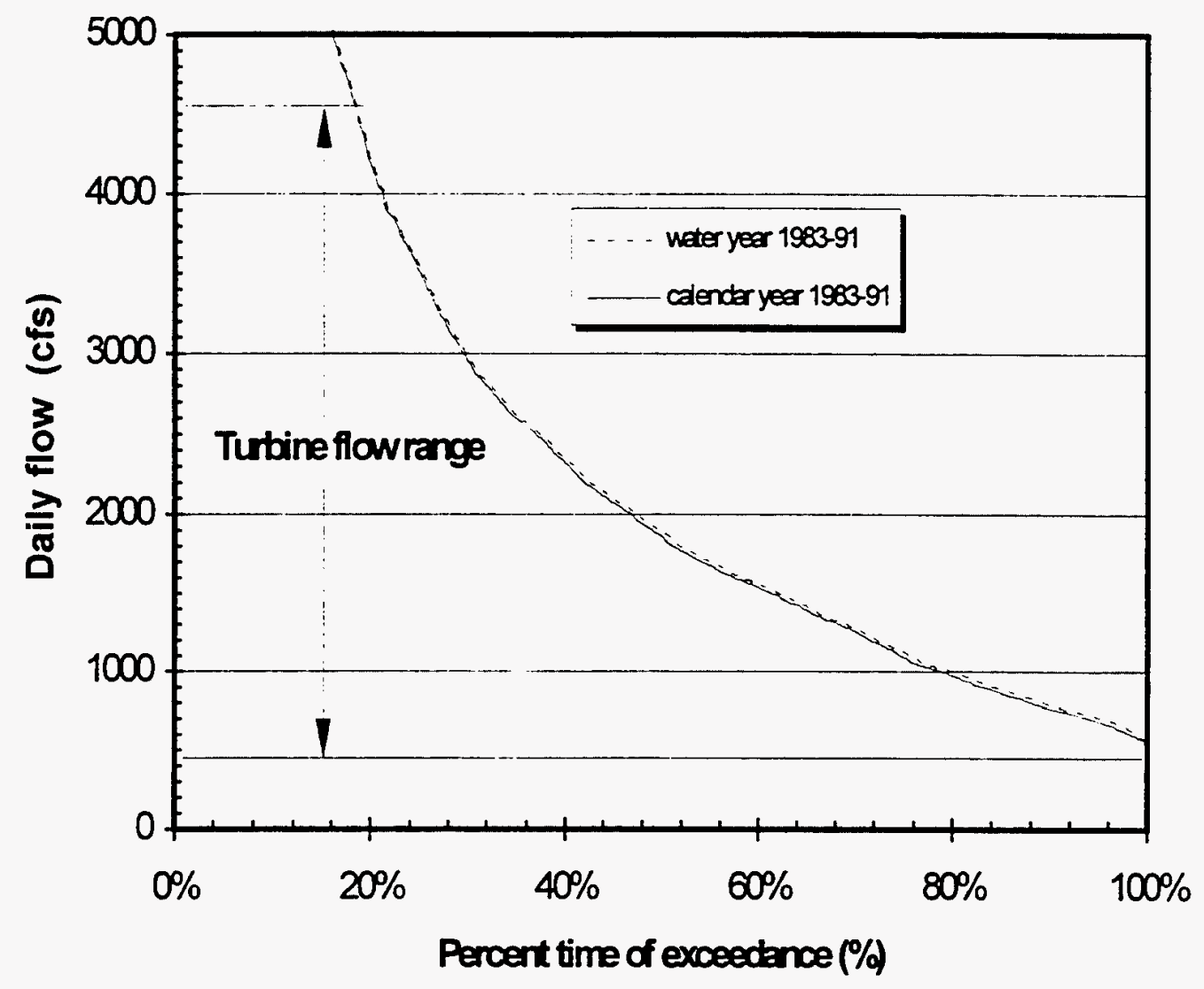

Fig. 4.4. Annual flow duration curve for Cushaw Hydropower Plant adjusted for drainage area based on USGS station 02025500 Holcomb Rock, James River. 


\subsubsection{Effects of a Variable Flow-head-efficiency Relationship}

The FDA method in use by the FERC employs a constant flow-power ratio factor (e.g., $1.66 \mathrm{~kW} / \mathrm{cfs}$ for Cushaw hydropower plant). The use of a constant flow-power ratio represents an average condition and will tend to overestimate energy at low flow conditions and underestimate energy at high flow conditions. Moreover, a constant flow-power ratio may not be accurate if there are nonuniform flow patterns, a nonlinear turbine efficiency curve, and the existence and operation of multiple generating units at a project site. More importantly, the energy gains depend on the alteration of flow patterns between the before and after flow conditions, therefore the error in flowpower ratio will be amplified. The enhanced FDA method or HWBFDA model incorporates a variable flow-hydraulic head relationship and turbine flow-power generation efficiency curve in calculation of power generation and hence energy gains. The basic water power equation is as follows:

$$
k W=e \times \frac{Q \times H}{11.8}
$$

where $\mathrm{kW}=$ power $(\mathrm{kW})$

$\mathrm{e}=$ combined turbine and generator efficiency,

$\mathrm{H}=$ net hydraulic head $(\mathrm{ft})$, and

$\mathrm{Q}=$ flow (cfs).

The efficiency is a function of turbine inflow, $\mathrm{e}=\mathrm{e}(\mathrm{Q})$. Hydraulic head, $\mathrm{H}$, is related to flow in the stage-discharge relationship $H=h(Q)$. Combining the efficiency curve and stage-flow rating curve, the power generation can be derived as a function of flow.

The annual energy gains for Cushaw Hydropower plant calculated by the enhanced FDA method are nearly $6 \%$ lower than those calculated by the constant flow power ratio when a flow step increment of $5 \mathrm{cfs}$ is used (Fig. 4.5). The difference increases significantly when a larger flow step is used in the analysis. The use of a constant flow-to-power ratio overestimates power generation at low flows and underestimates generation at high flows, as shown in Figure 4.6. The difference in power generation between the standard FDA method and the enhanced FDA method increases when inflow is greater than $3000 \mathrm{cfs}$ for this case study.

The correlation between the power generation and turbine inflow is often nonlinear, considering the variable flow-head-efficiency relationship (Fig. 4.6). However, the net impact on energy gains is more complicated because it depends on the difference between the power generated using flows before and after installation of upstream hydroprojects. Figure 4.7 shows the number of generator units in operation at various turbine inflow conditions. Cushaw hydropower plant has 5 identical generators with a total installed capacity of $7500 \mathrm{~kW}$ and total turbine flow capacity range of 500 to $4820 \mathrm{cfs}$. Because the hydropower plant is operated in a run-of-river mode, a linear stage-discharge relationship for operative flow range was assumed based on the information provided (Fig. 4.7). Since multipie units exist at the Cushaw Hydropower plant, the total combined efficiency curve is highly nonlinear (Fig. 4.8). As the number of units in operation increases, the combined efficiency converges. Figure 4.9 shows efficiency-power and flow-power relationships at various hydraulic heads. The flow-head-efficiency relationship was derived from these two sets of curves by assuming 




Fig. 4.5. Comparison of energy gains using flow power ratio and variable flow headefficiency for Cushaw Hydropower Plant. 


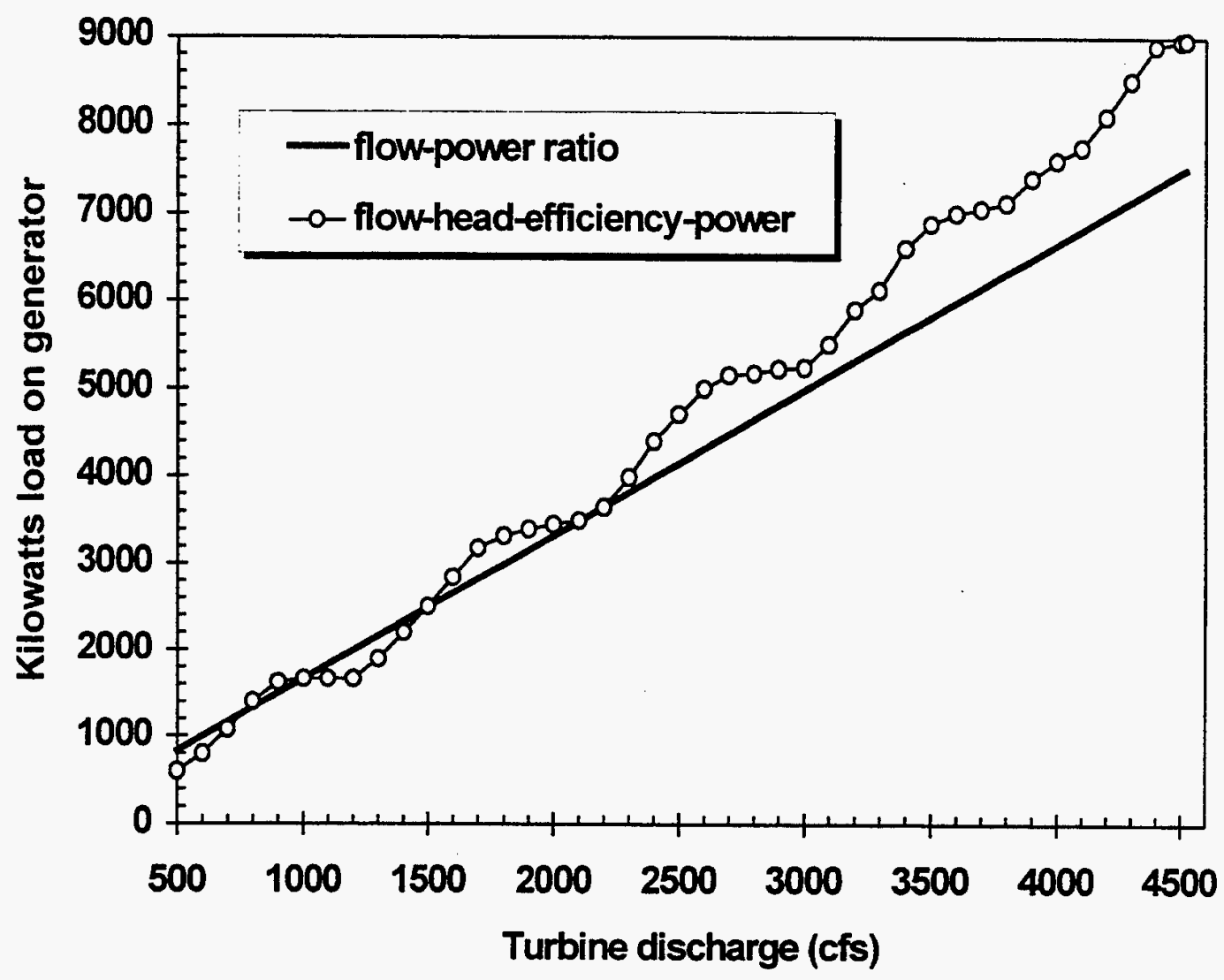

Fig. 4.6. Comparison of power generation between flow-power ratio and actual performance curves for Cushaw Hydropower plant. 


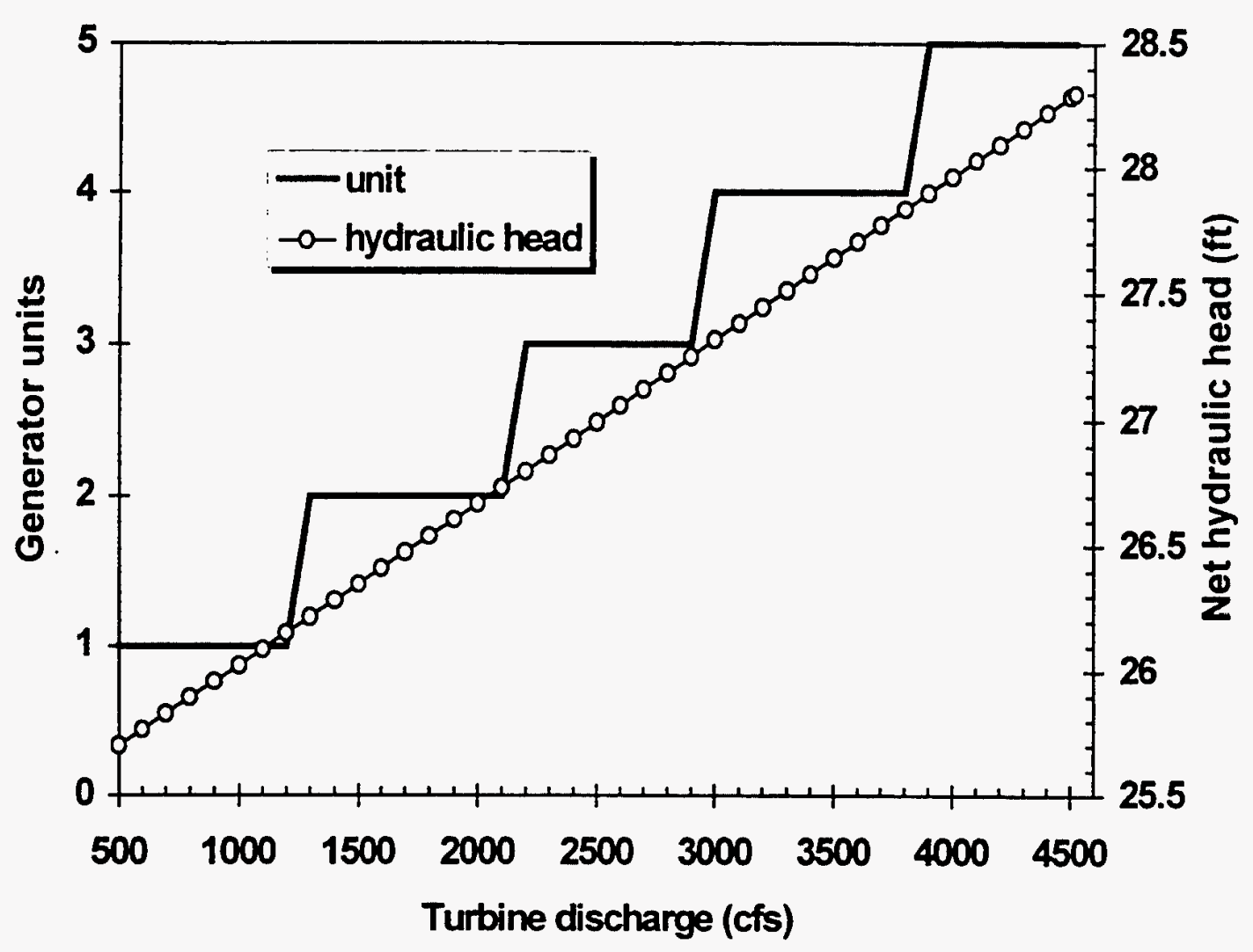

Fig. 4.7. Number of generators in operation and flow-stage relationship for Cushaw Hydropower Plant. 




Plant.

Fig. 4.8. Combined efficiency curve and power generation for Cushaw Hydropower 


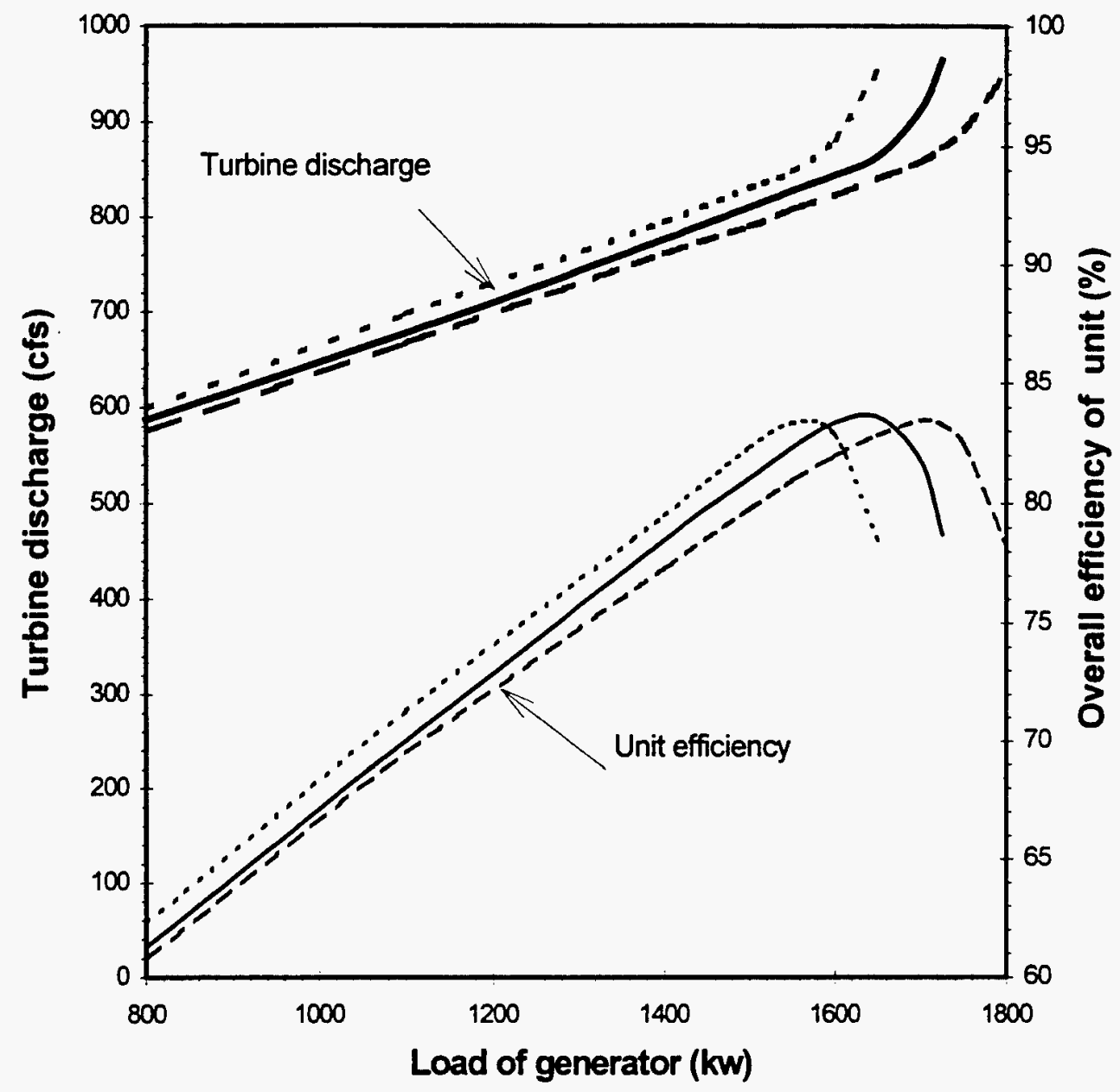

$$
\begin{array}{|l|l|}
\hline-q_{2} 26^{\prime} H D & -q_{2} 27 H D \\
\cdots \cdots-e_{2} 26^{\prime} H D & -q_{2} 28^{\prime} H D \\
\hline
\end{array}
$$

Fig. 4.9. Performance of turbine-generator unit at the Cushaw Hydropower plant. 
a linear stage-discharge (head-flow) relationship at a flows ranging of 500 to $4820 \mathrm{cfs}$, and a monotonic increase in power generation with turbine inflow.

\subsection{CONCLUSIONS}

The following conclusions can be made about the enhanced FDA method:

- High flow steps used in numerical integration affect energy gains calculations. Flow steps should not exceed $50 \mathrm{cfs}$. Considering the wide availability of high-powered PCs, a small flow step (e.g., $5 \mathrm{cfs}$ ) is recommended to minimize the numerical error and improve accuracy.

- The enhanced FDA method improves accuracy by 5 to $10 \%$ when using a variable flowhead-efficiency relationship.

- When flow data are limited, low flow data points may affect energy gains significantly. All available flow data should be used, if possible. Other approaches to overcome the data limitation should be explored. For instance, the FDA method can be modified to use flow after installation of the headwater project to derive the before unregulated flow, if no or very limited flow data before installation of upstream hydro project are available.

- The computer model HWBFDA was developed by ORNL to apply the enhanced FDA method specifically for three case studies, the James River, the Alabama River, and the Stanislaus River Basins. The source code (listed in Appendix A) can be modified for more generic application of the enhanced FDA method to run on PC computers. 


\section{COMPARISON OF ENERGY GAINS USING HWBEG AND ENHANCED FDA METHOD}

In this section, we apply the enhanced FDA method (HWBFDA Model) to estimate the energy gains at Logan Martin and Lay hydropower plants in Alabama River Basin and the Tulloch hydropower plant in Stanislaus River Basin. We then compare these results with those from the HWBEG model, discuss factors that affect FDA-calculated energy gains, and provide recommendations on when use of the FDA method is appropriate.

\subsection{RESULTS AND DISCUSSIONS}

Input data files for the enhanced FDA method for the Tulloch, Lay, and Logan Martin hydropower plants are listed in Tables 5.1-5.3, respectively. For the Lay and Logan Martin hydropower plants, we derived the power generation-to-turbine flow ratios based on data sets at each hydropower plant.

\subsubsection{Tulloch Hydropower Plant}

For the 1979-91 period, average annual energy gains computed by the HWBEG model are 14,533 MWh. By comparison, the annual energy gains calculated by the enhanced FDA method are 14,180 MWh with a minimum turbine flow of $30 \mathrm{cfs}$ and a flow increment for integration of $5 \mathrm{cfs}$. Figs. 5.1 and 5.2 show the flow duration curves for the Tulloch hydropower plant.

The enhanced FDA method underestimates energy gains by only $2.4 \%$ in comparison with HWBEG (Table 5.4). For a relatively simple river system such as the Stanislaus, in which the downstream plant operates in a run-of-river mode subject to flow regulation of one upstream storage reservoir, the enhanced FDA method is an appropriate and relatively accurate alternative to the HWBEG model.

\subsubsection{Lay Hydropower Plant}

The energy gains at the Lay hydropower plant calculated by the enhanced FDA method are nearly $80 \%$ higher tnan the energy gains computed by HWBEG over the $1974-82$ period (Table 5.4). Part of the difference may be explained by the presence of 282 points of zero flow data in the HWBEG MASTER.DAT file for flows after the installation of the headwater projects, shown in Figs. 5.3 and 5.4. The energy gain decreases at the low flow region, as shown in the flow duration curve for the Lay hydropower plant. When the minimum turbine flow $\left(\mathrm{Qt}_{\min }\right)$ is increased from $1500 \mathrm{cfs}$ to 2000 cfs, the energy gain will decline because of the greater slope of the flow duration curve for unregulated flows. When $\mathrm{Qt}_{\min }$ increases from $2000 \mathrm{cfs}$ to $3000 \mathrm{cfs}$, the energy gain will increase due to the slope change. If $\mathrm{Qt}_{\min }$ is greater than $5000 \mathrm{cfs}$, the energy gain will again decrease. 
Table 5.1 HWBFDA Input data file to estimate energy gains for Tulloch hydropower plant in the Stanislaus River Basin, CA

$\begin{array}{lll}11299500 . \text { dat } & ; & \begin{array}{l}\text { USGS gage station for unregulated flows } \\ \text { run for Tulloch powerplant } \\ \text { drainage area at gage station }\left(\mathrm{mi}^{2}\right)\end{array} \\ 905 . & ; & \begin{array}{l}\text { drainage area at dam site }\left(\mathrm{mi}^{2}\right) \\ \text { minimum turbine flow capacity }(\mathrm{cfs})\end{array} \\ 970 . & ; & \text { maximum turbine flow capacity }(\mathrm{cfs}) \\ 30 . & ; & \text { net head for power generation }(\mathrm{ft}) \\ 1830 . & ; & \begin{array}{l}\text { efficiency for power generation } \\ \text { incremental flow for power integration (cfs) }\end{array} \\ 144 . & ; & \begin{array}{l}\text { output for FD curve before HW project } \\ 0.85\end{array} \\ 5 . & ; & \begin{array}{l}\text { output for FD curve after HW project } \\ \text { regulated flows data (after HW project installed) }\end{array} \\ \text { tull-qb.out } & ; & \text { main output file }\end{array}$

Table 5.2 HWBFDA Input data file to estimate energy gains for Lay hydropower plant in the Alabama River Basin, AL

\begin{tabular}{|c|c|c|}
\hline $2407000 . f l w$ & & USGS flow gage station data file (before) \\
\hline & & run for Lay \\
\hline 8392. & & drainage area at gage station $\left(\mathrm{mi}^{2}\right)$ \\
\hline 9087. & & drainage area at dam site $\quad\left(\mathrm{mi}^{2}\right)$ \\
\hline 4500 . & & minimum turbine flow capacity (cfs) \\
\hline 32919. & & maximum turbine flow capacity (cfs) \\
\hline 85 & & net head for power generation (ft) \\
\hline 0.78 & & efficiency for power generation \\
\hline 5. & & incremental flow for power integration (cfs) \\
\hline lay- & & output for FD curve before $\mathrm{HW}$ project \\
\hline lay-ga. out & & output for FD curve after HW project \\
\hline masterd.ala & & flow data after $H W$ project \\
\hline lay-fda.out & & main output file name \\
\hline
\end{tabular}


Table 5.3 HWBFDA Input data file to estimate energy gains for Logan Martin hydropower plant in the Alabama River Basin, $\mathrm{AL}$

\begin{tabular}{|c|c|c|}
\hline 2407000.flw & ; & USGS flow gage station data file (before) \\
\hline 1 & & run for Martin \\
\hline 8392. & & drainage area at gage station $\left(\mathrm{mi}^{2}\right)$ \\
\hline 7700 . & & drainage area at dam site $\left(\mathrm{mi}^{2}\right)$ \\
\hline 10200. & & minimum turbine flow capacity (cfs) \\
\hline 34385. & & maximum turbine flow capacity (cfs) \\
\hline 55 & & net head for power generation (ft) \\
\hline 0.75 & & efficiency for power generation \\
\hline 5. & & incremental flow for power integration (c) \\
\hline mar-qb.out & & output for FD curve before HW project \\
\hline mar-qa.out & & output for FD curve after HW project \\
\hline masterd.ala & & flow data after $\mathrm{HW}$ project \\
\hline mar-fda.out & & main output file name \\
\hline
\end{tabular}

Table 5.4 Comparison of energy gains calculated using HWBEG and enhanced FDA methods.

\begin{tabular}{l|c|c|c|l|l|l}
\hline \multirow{2}{*}{ Method } & \multicolumn{4}{|c|}{ Parameters } & \multicolumn{3}{c}{ Annual energy gains (MWh) } \\
\cline { 2 - 7 } & Efficiency & $\begin{array}{c}\text { Minimum } \\
\text { turbine flow } \\
\text { (cfs) }\end{array}$ & $\begin{array}{c}\text { Net hydraulic } \\
\text { head } \\
\text { (ft) }\end{array}$ & Tulloch & Lay & Logan Martin \\
\hline HWBEG & - & - & - & 14533 & 42593 & 26330 \\
\hline $\begin{array}{l}\text { Enhanced } \\
\text { FDA }\end{array}$ & 0.85 & 30 & 144 & 14180 & - & \\
\cline { 2 - 7 } & 0.78 & 4500 & 85 & & 76373 & \\
\cline { 2 - 7 } & 0.75 & 10200 & 55 & - & - & 74994 \\
\hline $\begin{array}{l}\text { Difference } \\
\text { in energy } \\
\text { gains by } \\
\text { HWBEG } \\
\text { and FDA }\end{array}$ & - & - & - & $-2.4 \%$ & $79.3 \%$ & $184.8 \%$ \\
\hline
\end{tabular}




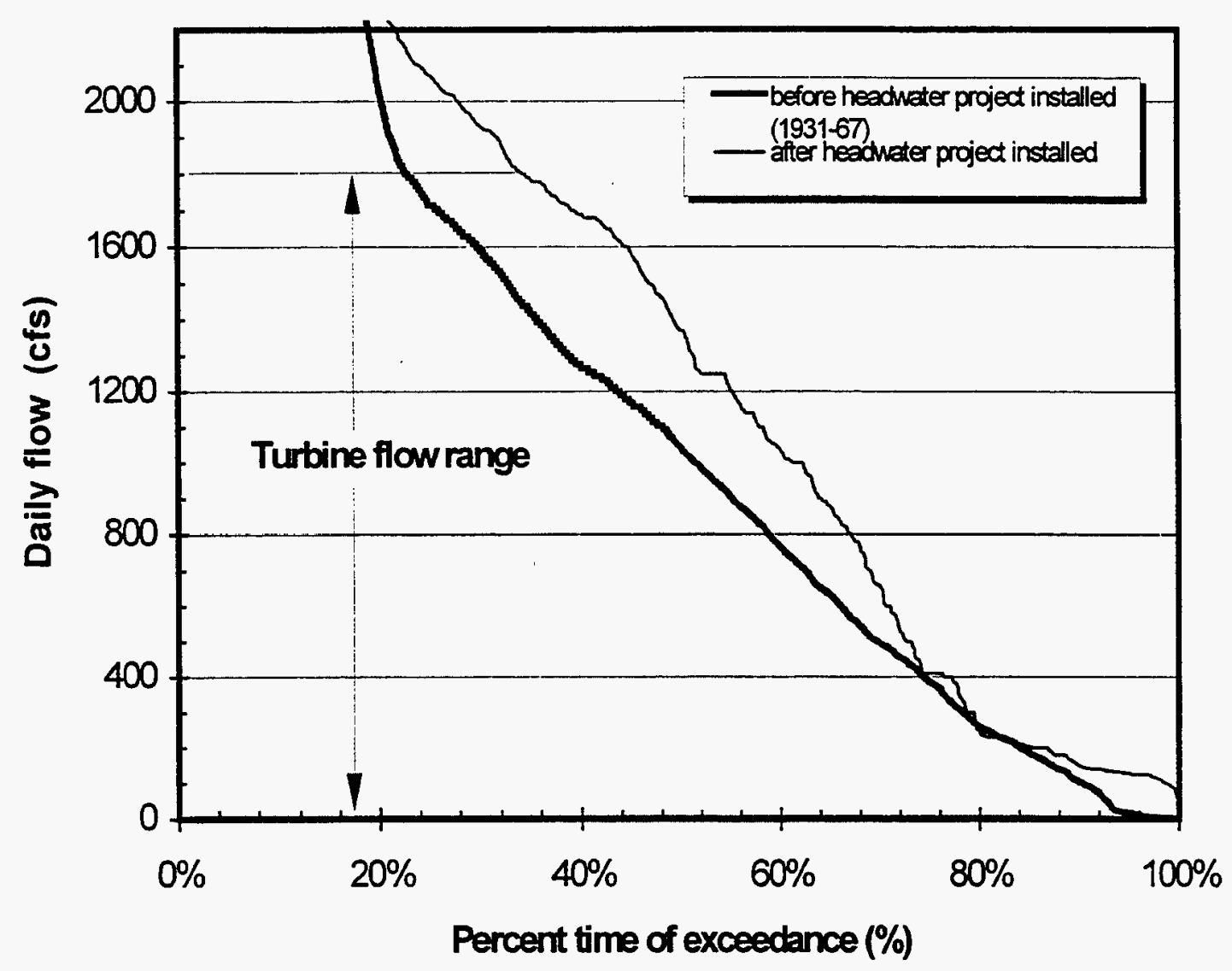

Fig. 5.1. Annual flow duration curve for Tulloch Hydropower Plant adjusted for drainage area based on USGS station 11299500, Stanislaus River (0 to 2,200 cfs flow range). 


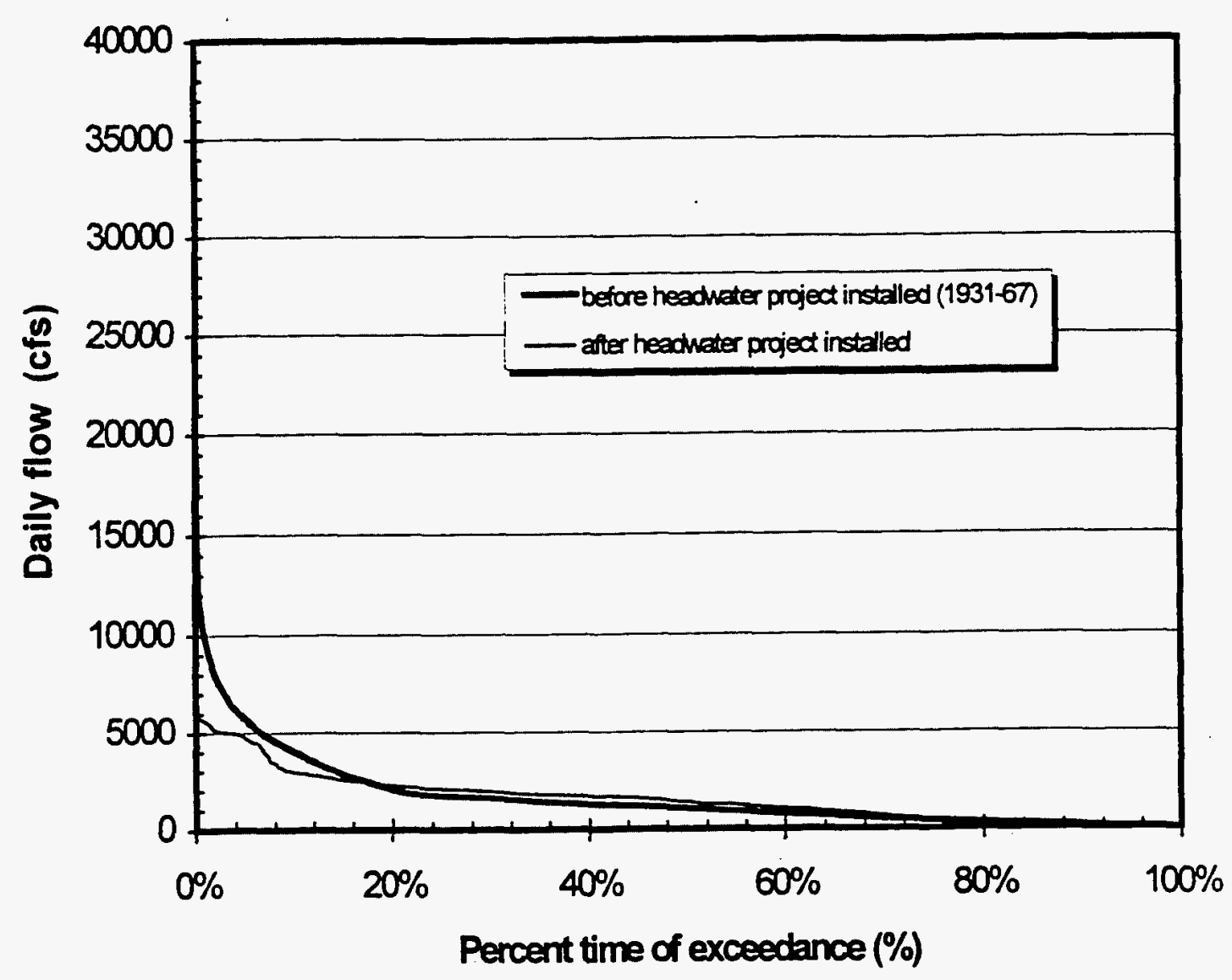

Fig. 5.2. Annual flow duration curve for Tulloch Hydropower Plant adjusted for drainage area based on USGS station 11299500, Stanislaus River (0 to 40,000 cfs flow range). 


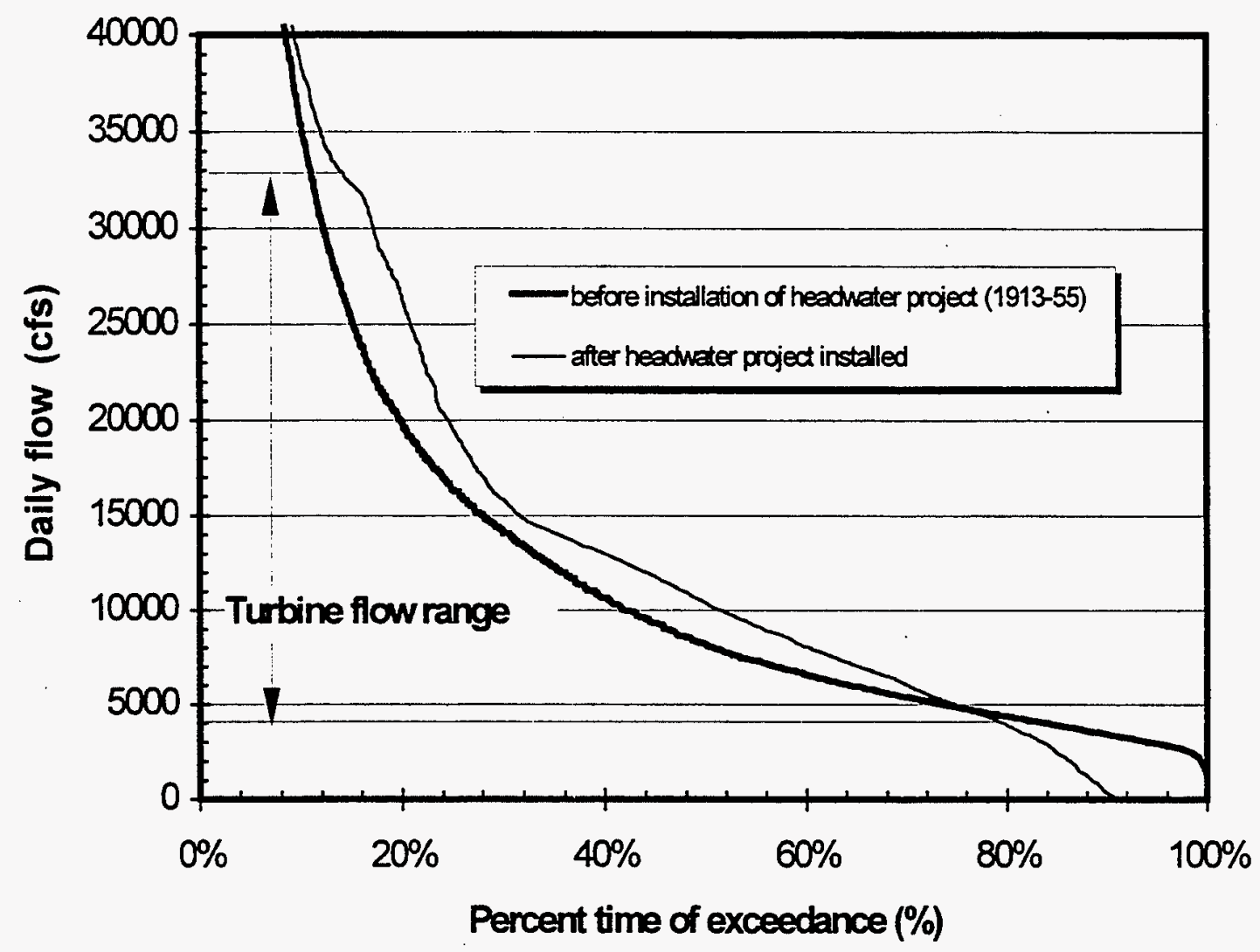

Fig. 5.3. Annual flow duration curve for the Lay Hydropower Plant adjusted for drainage area based on USGS station 02407000, Alabama River (0 to 160,000 cfs flow range). 


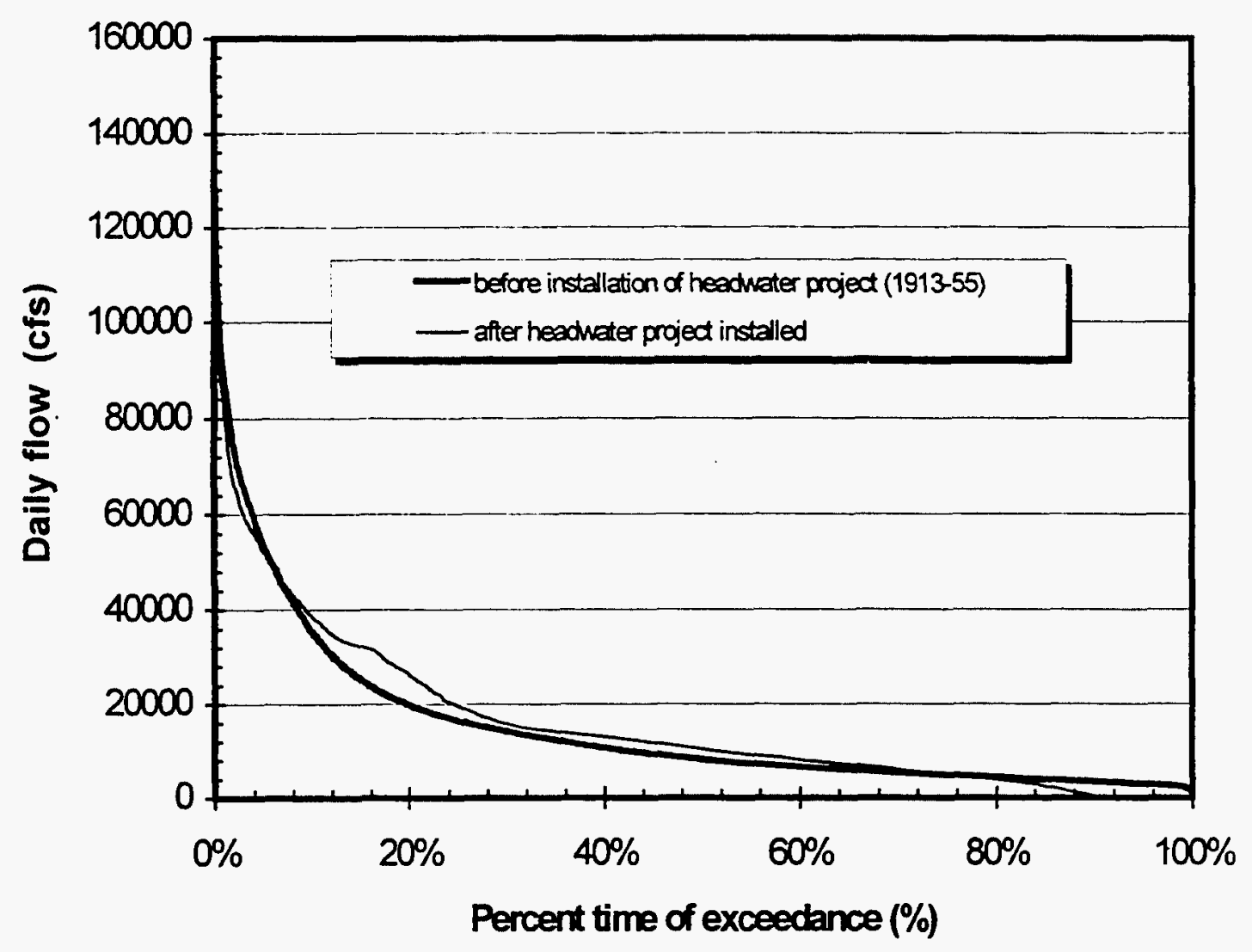

Fig. 5.4. Annual flow duration curve for the Lay Hydropower Plant adjusted for drainage area based on USGS station 02407000, Alabama River (0 to 40,000 cfs flow range). 


\section{Logan Martin hydropower plant}

Average annual energy gains computed by HWBEG over 9 years (1974-82) are 26,330 MWh. The annual energy gain calculated by the enhanced FDA method are 74,994 MWh assuming a hydropower generation efficiency of 0.75 and net hydraulic head of $55 \mathrm{ft}$. The minimum turbine flow used is $10,200 \mathrm{cfs}$ with a net hydraulic head of $55 \mathrm{ft}$. Both hydropower efficiency and net head have impacts on the calculated energy gains. Because of the 343 points of zero flow data in the MASTER.DAT file for flows after the headwater projects were installed, the energy gains decline at the low flow region. When the minimum turbine flow $\left(\mathrm{Qt}_{\min }\right)$ is increased from $1500 \mathrm{cfs}$ to $2000 \mathrm{cfs}$, the energy gains decline because of the greater flow slope of the flow duration curve for unregulated flows. When $\mathrm{Qt}_{\min }$ is increased from $2000 \mathrm{cfs}$ to $3000 \mathrm{cfs}$, the energy gains increase, and decrease again if the $\mathrm{Qt}_{\min }$ is greater than 4000 cfs (Figs. 5.5 and 5.6).

\subsection{FACTORS AFFECTING HEADWATER BENEFITS ESTIMATES USING FDA METHOD}

\subsubsection{Length Of Data Period}

See discussion in Section 3.

\subsubsection{Flow Step}

The flow step increment $(\Delta q)$ chosen for the numerical integration was discussed in Section 3. Results from baseline case study for the Cushaw hydropower plant in James River Basin show that the choice of the increment size is important. Higher $\Delta \mathrm{q}$ values will result in larger differences (6 to $15 \%$ ) in calculated energy gains. The HWBEG model and FDA method comparative results indicate that the $\Delta \mathrm{q}$ should be less than $50 \mathrm{cfs}$ to minimize the impact of flow increment on energy gain calculations.

\subsubsection{Starting Point For Integral}

The impact of minimum turbine discharge on calculated energy gains depend on (1) the change of slope at the low flow points on flow duration curves for unregulated and regulated flows and (2) position of the flow duration curves (indicating energy gains or energy losses at the low flow range).

\subsubsection{Ending Point For Integral}

Energy gains depend on the turbine flow capacities (minimum and maximum flow discharge). As illustrated in the flow duration curve for the Tulloch Hydropower plant, the headwater project (New Melones Reservoir) provides significant energy gains with the maximum turbine flow capacity of $1830 \mathrm{cfs}$. However, the energy gains may become negative if the maximum turbine flow capacity is increased hypothetically to $10,000 \mathrm{cfs}$. 


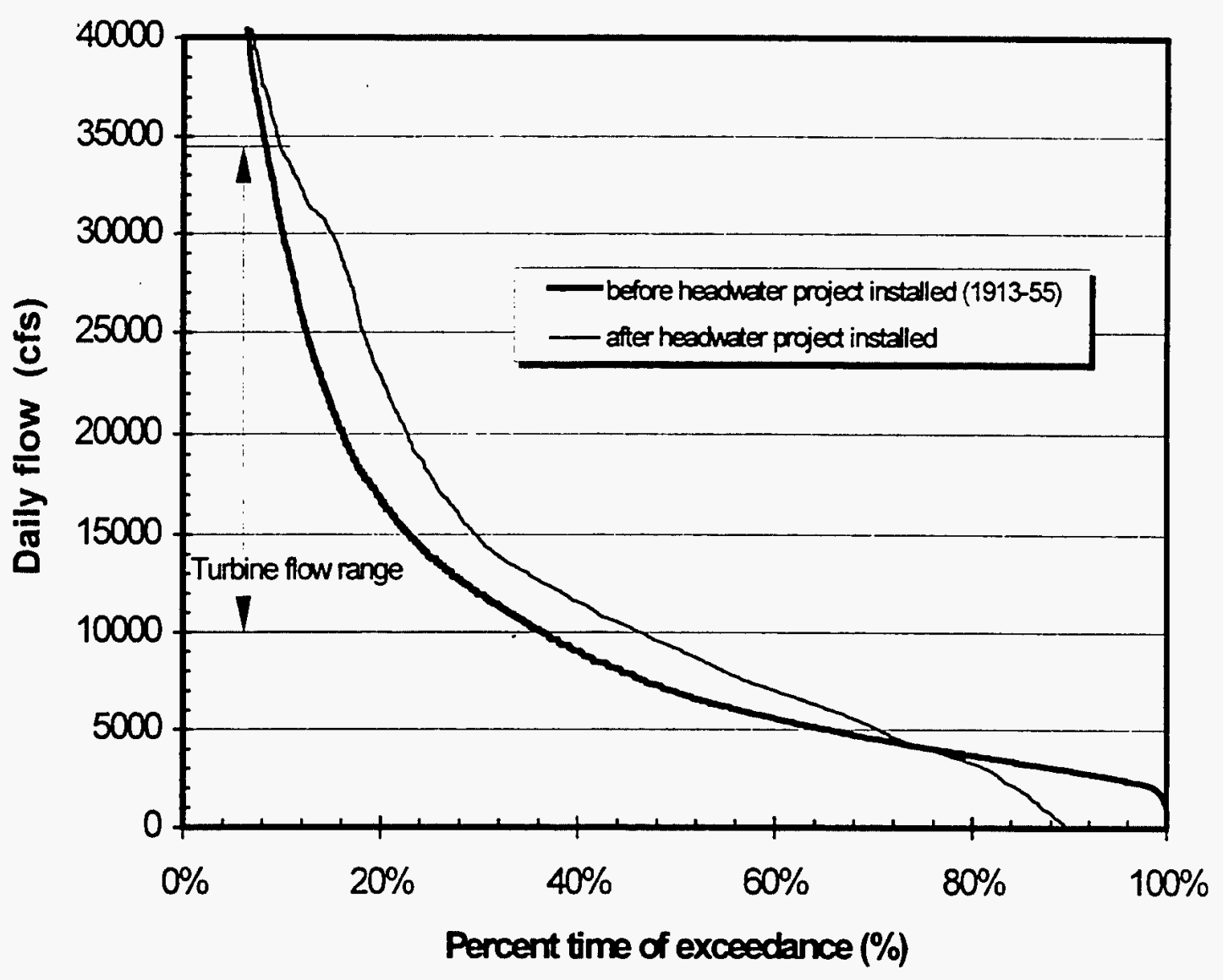

Fig. 5.5 Annual flow duration curve for Logan Martin hydropower plant adjusted for drainage area based on USGS Station 02407000, Alabama River (0 to 40,000 cfs flow range). 


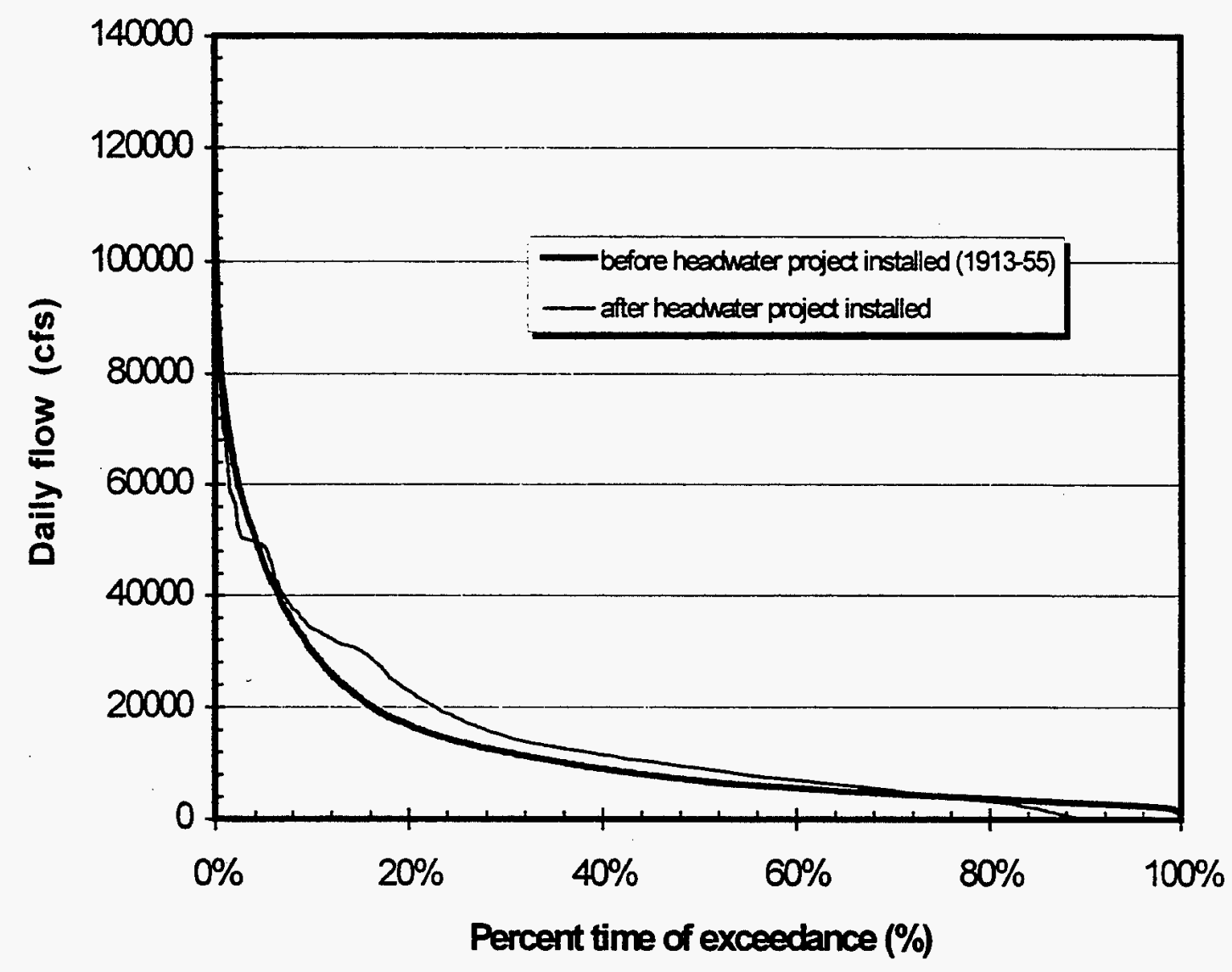

Fig. 5.6 Annual flow duration curve for Logan Martin hydropower plant adjusted for drainage area based on USGS Station 02407000, Alabama River ( 0 to 140,000 cfs flow range). 


\subsubsection{Incorrect Flow Data}

The flow data for after the installation of headwater projects in the Alabama River Basin are recorded in MASTER.DAT file. The negative inflows in the MASTER.DAT file need to be corrected, usually manually outside of the HWBEG model. If the negative inflows are not corrected, the river flow generated afterwards will be inaccurate. These errors will also affect the flow duration curves. If these negative inflows are replaced by zero in the MASTER.DAT file, then the entire flow duration curve shifts downwards, having the effect of decreasing energy gains. For instance, the minimum daily flow recorded at the Lay hydropower plant during the 1913-55 period is $1408 \mathrm{cfs}$, and yet there are 282 points of zero flow in the MASTER.DAT file. Because the Lay hydropower plant is operated in run-of-river mode and it is a relatively large river ( $7500 \mathrm{cfs}$ median daily flow), it does not seem reasonable to have a situation in which there are no outflows $10 \%$ of time. This strongly suggests possible data entry or recording errors. However, the presence of zero flow points for the Logan Martin hydropower plant and reservoir could mean that water is being stored (zero outflows) for higher energy gains at high flows (altering the flow duration curve).

\subsubsection{Constant Flow-power Ratio vs Variable Hydraulic Head and Efficiency}

As shown in the study of the Cushaw hydropower plant in the James River Basin, there is a difference of 2 to $6 \%$ in calculated energy gains between the constant flow-power and variable hydraulic head and efficiency methods. This difference in computed energy gains also increases when larger flow increments $(\Delta q)$ are used. In the James River baseline case, the enhanced FDA method incorporating variable efficiency produces higher hydropower, but lower energy gains.

\subsubsection{Complexity of River System}

Comparing the Stanislaus and Alabama River Basins, the FDA method is clearly better in the simpler systems. However, the FDA is inappropriate for a complex system, such as the Alabama River. Although this conclusion is based on limited testing, the high degree of re-regulation of flows will likely preclude the use of the FDA method in complex basins.

\subsection{CONCLUSIONS}

In principle, the FDA method as used in the James River Basin is valid (FERC, 1993b) and can be used in other basins, such as the Stanislaus. However, the standard FDA method, as currently used by the FERC, can be enhanced by using:

- more automated procedures,

- $\quad$ smaller flow step increments to minimize the numerical errors in calculation of power gen:ration;

- a variable flow-head-efficiency relationship; and

- being able to derive unregulated flows when necessary.

In summary, FDA works reasonably well for a simple river basins such as the Stanislaus River Basin. However, for a complex river-reservoir system, such as the Alabama River Basin, the FDA method overestimated the annual energy gains (by as much as $185 \%$ at Logan Martin). The FDA method is not recommended for use in complex river basins that are subject to a high degree of flow regulation. 


\section{FINDINGS}

This study reports on ORNL's attempt to validate for accuracy and appropriateness the standard FDA method for determining energy gains. Two river basins, the Alabama and Stanislaus, were used to make a comparative evaluation of the FDA method with the validated and documented HWBEG model. In addition to validating the FDA method for accuracy, a number of improvements and enhancements were made to FDA method. The following findings are offered based on an explicit comparison of the HWBEG model and the FDA method.

- Application of HWBEG model to the Alabama and Stanislaus River Basins confirmed the results reported in previous published headwater benefit determinations.

- The use of the monthly data option in the HWBEG model is an inferior method for calculating energy gains. Generally, the use of monthly data tends to result in lower energy gains. This is due to the "smoothing" effect of monthly flow data. It is only appropriate as a general screening tool as discussed in the PC version of the HWBEG model.

- The standard FDA method is an appropriate method to use in making determinations in river basins that are not complex. In these non-complex river basins, such as the Stanislaus, the FDA method provided a good approximation to the HWBEG model based on daily data. However, for a complex river-reservoir system such as Alabama River Basin, the FDA method overestimated the annual energy gains.

- The standard FDA procedures in use by FERC can be automated and enhanced as follows:

High flow steps used in numerical integration affect energy gains calculations. Although the impact of flow step on energy gains calculations becomes insignificant when the flow step is less than $50 \mathrm{cfs}$, a small flow step (e.g., 5 cfs) is recommended to minimize the numerical error and improve accuracy.

- More accurate results can be obtained by using a variable flow-headefficiency relationship rather than a constant power-to-flow relationship. The HWBFDAV model incorporates a variable flow-head-efficiency relationship to enhance the FDA method. The enhanced FDA method improves accuracy by 5 to $10 \%$ and should be used.

- When flow data is limited, low flow data points may distort energy gains calculations significantly. New approaches to overcome data limitations should be explored. For instance, the FDA method can be modified to use flow after installation of headwater project to derive the before (unregulated) flow, if no or very few flow data before installation of upstream hydro project are available.

- Because the scope of this study was limited to two basins and to one or two projects within each basin, it was not possible to address the basin complexity issue in great detail. Suffice it to say that the FDA method is appropriate for use in the James, Stanislaus River Basins, and other similar sized basins and inappropriate for complex basins such as the Alabama River Basin involving a high degree of flow regulation. 


\section{REFERENCES}

Code of Federal Regulations (CFR), Title 18, April 1, 1994.

Federal Energy Regulatory Commission (FERC), Determination of Headwater Benefits: Stanislaus River Basin, Division of Project Compliance and Administration, OHL Docket No. HB43-91-1-000, Washington, August 1992.

Federal Energy Regulatory Commission (FERC), The Microcomputer Fortran Version of the Headwater Benefits Energy (HWBEG) Gains Model, Division of Project Compliance and Administration, Washington, June 1993a.

Federal Energy Regulatory Commission (FERC), Summary Report of Headwater Benefits: James River Basin, Division of Project Compliance and Administration, OHL Docket No. HB68-93-6, Washington, December 1993b.

Perlack, R. $\perp$ Turhollow, S. Cohn, S. Das, C. Rizy, J. Tulley, and R. Kreamer, Headwater Benefits Energy Gains Model Description and Users Manual, Oak Ridge National Laboratory, ORNL/TM8395, Prepared for the Energy Information Administration and the Federal Energy Regulatory Commission, Oak Ridge, Tennessee, February 1984a.

Perlack, R. D., A. F. Turhollow, and D. L. Johnson, The Allocation and Apportionment of Joint-use Cost to Power: a Report on the Assessment of Headwater Benefit Charges, Oak Ridge National Laboratory, ORNL/TM-9165, Prepared for the Energy Information Administration and the Federal Energy Regulatory Commission, Oak Ridge, Tennessee, October 1984b.

Turhollow, A., S. Das, D. Flanagan, R. Perlack, H. Tsao, J. Tulley, and R. Kraemer, An Evaluation of the Headwater Benefits Energy Gains (HWBEG) Model, Oak Ridge National Laboratory, ORNL/TM-8726, Prepared for the Energy Information Administration and the Federal Energy Regulatory Commission, Oak Ridge, Tennessee, February 1985.

Vogel, R. M. And N. M. Fennessey, "Flow Duration Curves II: A Review of Applications in Water Resources Planning," Water Resources Bulletin, 31(6):1029-1039, December, 1995. 


\section{APPENDIX}

\section{COMPUTER CODE}


program hwbfda

c

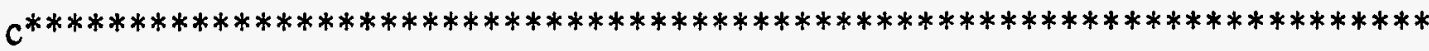

c HWBFDA is developed to estimate the Head Water Benefit (energy

c gains) due to the upstream hydropower projects using Flow

c Duration Analysis method.

c

c Written by: Steve Bao

c

c

Environmental Sciences Division

Oak Ridge National Lab

C

C

c Revised:

April 24, 1996

c (1) $5 / 2 / 96$ changed ratioc from input parameter to

c internal variable to be calculated.

c

c

c

Will be improved by add $e=e(q)$, and $H=h(q)$.

(2) $5 / 3 / 96$ add a function to calculate ratio of power to turbine flow as a variable instead of a constant

(3) $7 / 18 / 96$ use flow data after headwater projects being installed only, the flow data before installation is derived from $I=Q+d s / d t$ applied to projects in Stanislaus River basin.

Note: (1) The integration is carried out $\mathrm{KW}(\mathrm{q}(\mathrm{p}(\mathrm{t}))) \mathrm{dt}$.

c This program is provided "as is" without any express or

c implied warranty. ORNL shall not be liable for any direct,

c indirect, special or consequential damages resulting from the

c loss of use, data or projects, whether in an action of

c contract or tort, arising out of or in connection with the use

c or performance of this code.

c

$c^{*}$

c Input variables:

c

c filea $=$ file name of input regulated stream flow data

c fileb = file name of input unregulated stream flow data

c fileout $=$ output file name

c idam = indicate which proposed project considered

c $1:$ Logan-Marin

c $\quad 2:$ Lay

c $3:$ Tulloch 


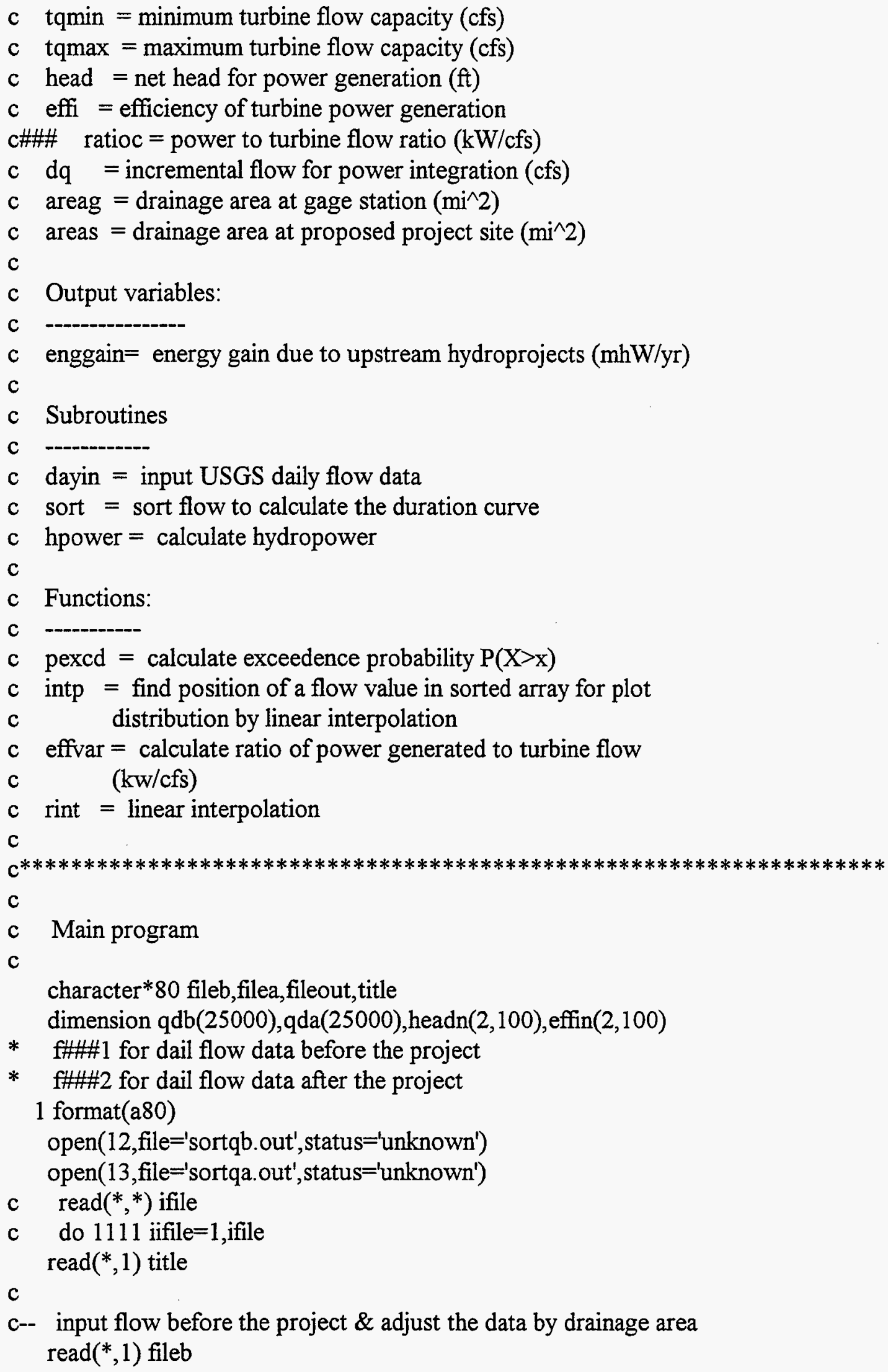




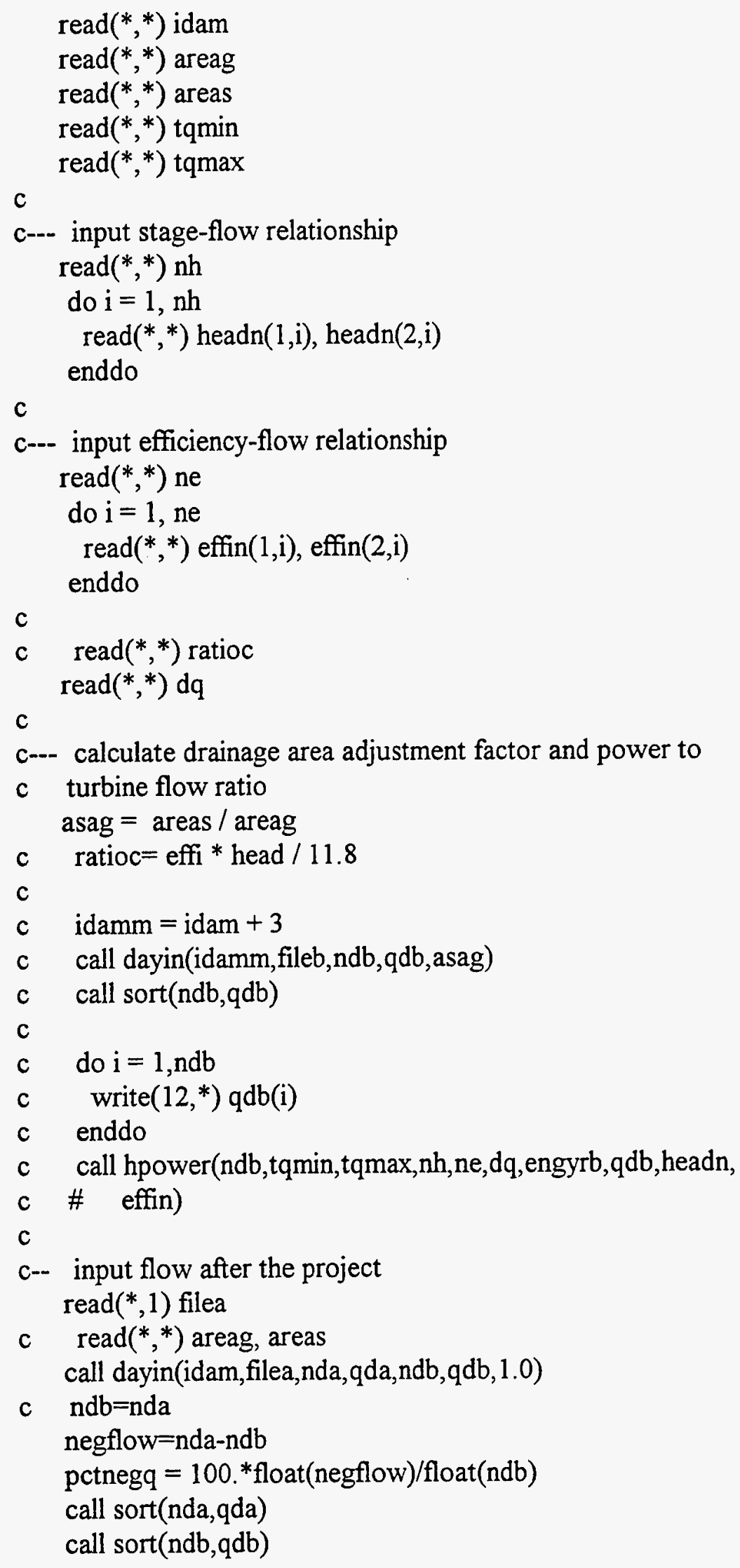


c

do $\mathrm{i}=1, \mathrm{ndb}$

write $\left(12,{ }^{*}\right) \mathrm{qdb}(\mathrm{i})$

enddo

call hpower(ndb,tqmin,tqmax,nh,ne,dq, engyrb, qdb, headn,

\# effin)

c

do $\mathrm{i}=1, \mathrm{nda}$

write $(13, *)$ qda(i)

enddo

call hpower(nda,tqmin,tqmax,nh,ne,dq,engyra,qda, headn,

\# effin)

c

enggain $=$ engyra - engyrb

c

c---- print the results

c

$\operatorname{read}(*, 1)$ fileout

open(unit $=6$, status $=$ 'unknown', file=fileout)

write $(6,100)$ title,filea,fileb, fileout, areag,areas,

\# tqmin,tqmax,dq, engyrb, engyra, enggain,negflow,pctnegq

c \# enggain

100 format $(/ / 10 \mathrm{x}, \mathrm{a} 80 / /$

$\# 11 \mathrm{x}, 1 * * * * * * * * * * * * * * * * * * * * * * * * * * * * * * * * * * * * * * * * * * * * * * * * * * * * * * * * 1 /$

$\# 11 \mathrm{x}$,*

*1/

\#11x, ${ }^{*}$ Preliminary Results of Flow Duration Analysis *y

$\# 11 x^{1 *}$

$* 1$

$\# 11 \mathrm{x},{ }^{1 * * * * * * * * * * * * * * * * * * * * * * * * * * * * * * * * * * * * * * * * * * * * * * * * * * * * * * * * * * * * * * 1 / /}$

$\# 11 \mathrm{x}$,'input regulated flow file $=$ ',a80/

$\# 11 \mathrm{x}$,'input unregulated flow file $=$ ',a80/

$\# 11 x$,'output of FDA results file $=$,a80/

$\# 11 \mathrm{x}$,'drainage area at gage station $=$ ',f10.1,' $\mathrm{mi}^{\wedge} 2^{\prime} /$

$\# 11 \mathrm{x}$,'drainage area at dam site = ',fl0.1,' $\mathrm{mi}^{\wedge} \mathrm{2}^{\prime} /$

$\# 11 \mathrm{x}$,'minimun turbine flow capacity = ',f10.1,' cfs'/

\#11x,'maximun turbine flow capacity = ',fl0.1,' cfs'/

\#11x,'flow increment for integration= ',fl 0.1 , $\mathrm{cfs}^{\prime}$ '

\#11x,'w/o upstream reservoirs = ',fl2.2,' $\mathrm{mhw} / \mathrm{yr} /$

$\# 11 \mathrm{x},{ }^{\prime} \mathrm{w} / \mathrm{upstream}$ reservoirs = ',f12.2, $\mathrm{mhw} / \mathrm{yr} /$

\#11x,'energy gain = ',f12.2,' mhw/yr'/

$\# 11 x$,'number of negative flow data $=$ ',i12, ' days'/

\#11x,'percentage of negative flow =',f12.2,' (\%)')

c 111 continue

stop

end

c 


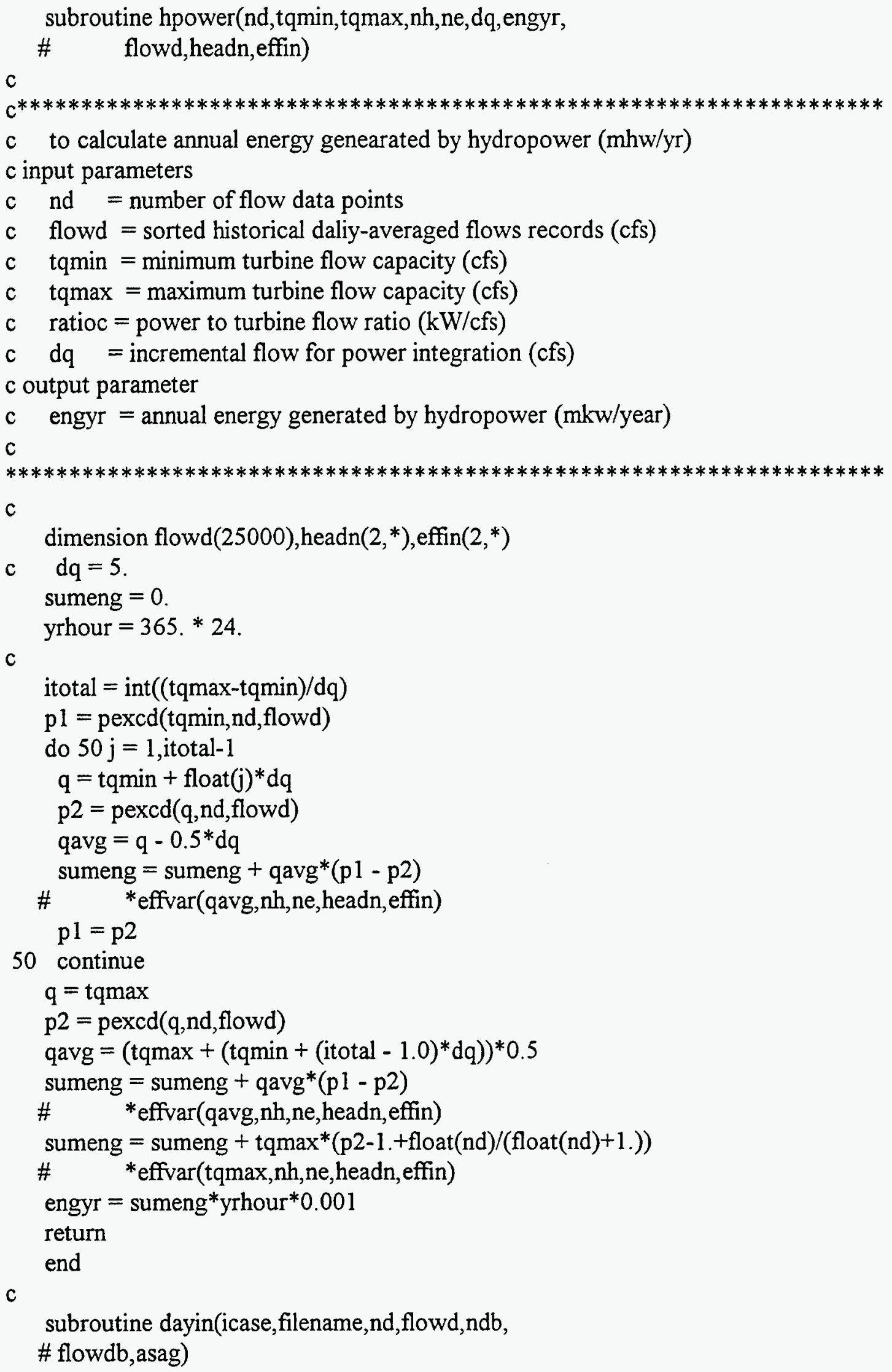


C

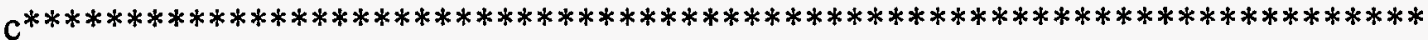

c to input daily flow averaged flow (cfs) from HWBEG master.dat

c -- regulated flow data with upstream hydroprojects, or

c to read USGS daily flows (cfs) into an array flowd (cfs)

c -- unregulated flow before the upstream hydrprojects

c were built.

C

c icase $=$

c 1: Martin reservoir on Alabama river basin, (HWBEG master.dat)

c 2: Lay reservoir on Alabama river basin, (HWBEG master.dat)

c 3: Stanislaus River Basin, (HWBEG master.dat)

c 4: Marin unregulated flow

c 5: Lay unregulated flow

c 6: Stanislau river basin unregualted flow

c

c asag $=$ drainage area adjustment factor which is ratio of

c drainage area at dam site drainage area at gauge

c station site

$\mathrm{c} * * * * * * * * * * * * * * * * * * * * * * * * * * * * * * * * * * * * * * * * * * * * * * * * * * * * * * * * * * * * * * * * * * * * *$

c

character* $\left(^{*}\right)$ filename

dimension flowd(25000), flowdb(25000)

open(unit $=10$, status $=$ 'old', file=filename)

c

nd $=0$

$\mathrm{ndb}=0$

goto $(100,200,300,400,500,600)$ icase

c

c-- to daily flow data points

$\mathrm{c}$

c-- for Martin Reservoir on Alabama river basin icase $=1$

$100 \mathrm{read}(10,15$, end $=999)$ imon

if(imon.eq.0) goto 100

backspace 10

$\operatorname{read}\left(10,{ }^{*}\right.$, end $\left.=999\right) \mathrm{d} 1, \mathrm{~d} 2, \mathrm{~d} 3, \mathrm{~d} 4, \mathrm{~d} 5, \mathrm{qm}$

read $(10, *$,end $=999)$

if(qm.ge.0.) then

nd $=$ nd +1

flowd $(n d)=q m$

endif

goto 100

15 format $(2 \mathrm{x}, \mathrm{i} 2)$

c

200 read $(10,15$, end=999) imon 


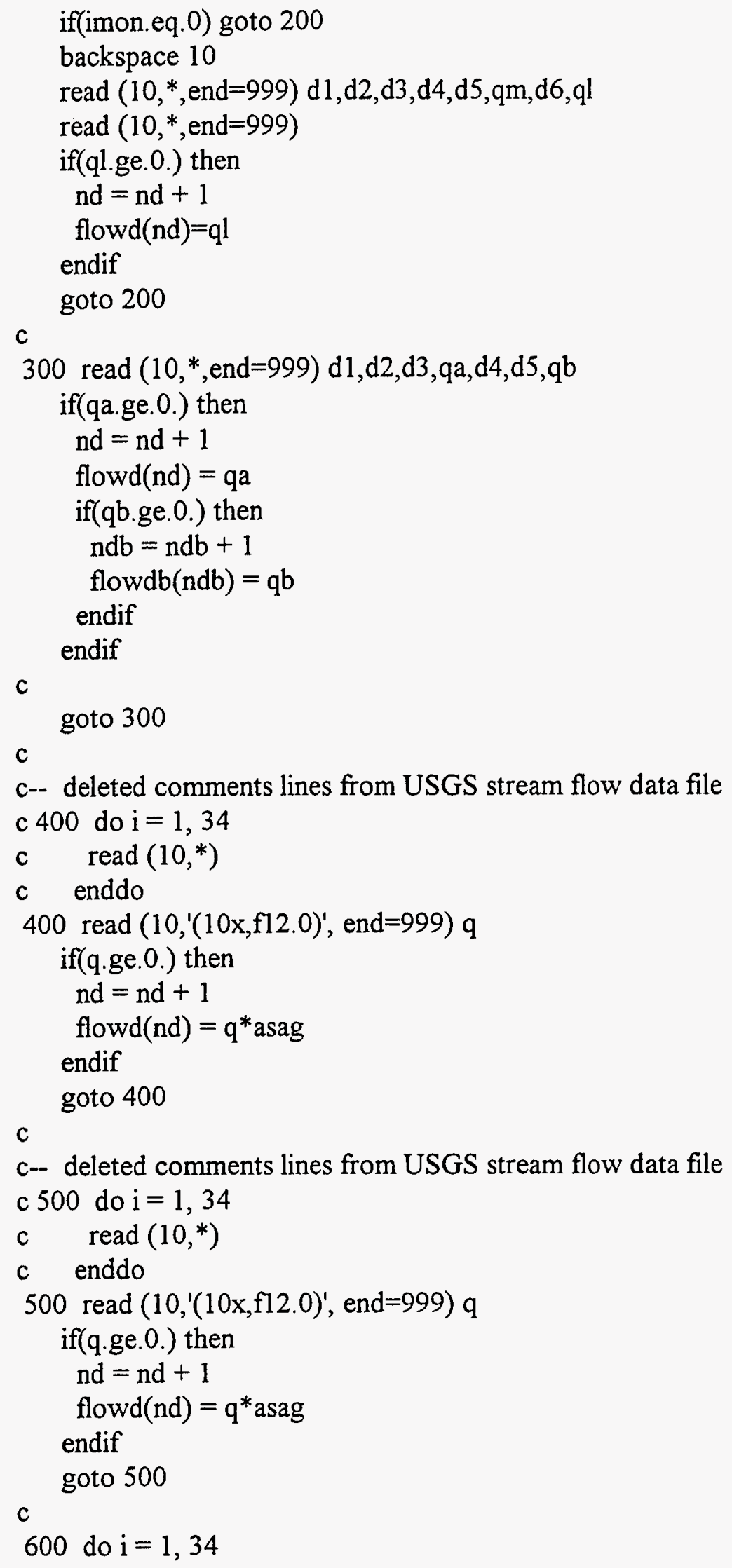




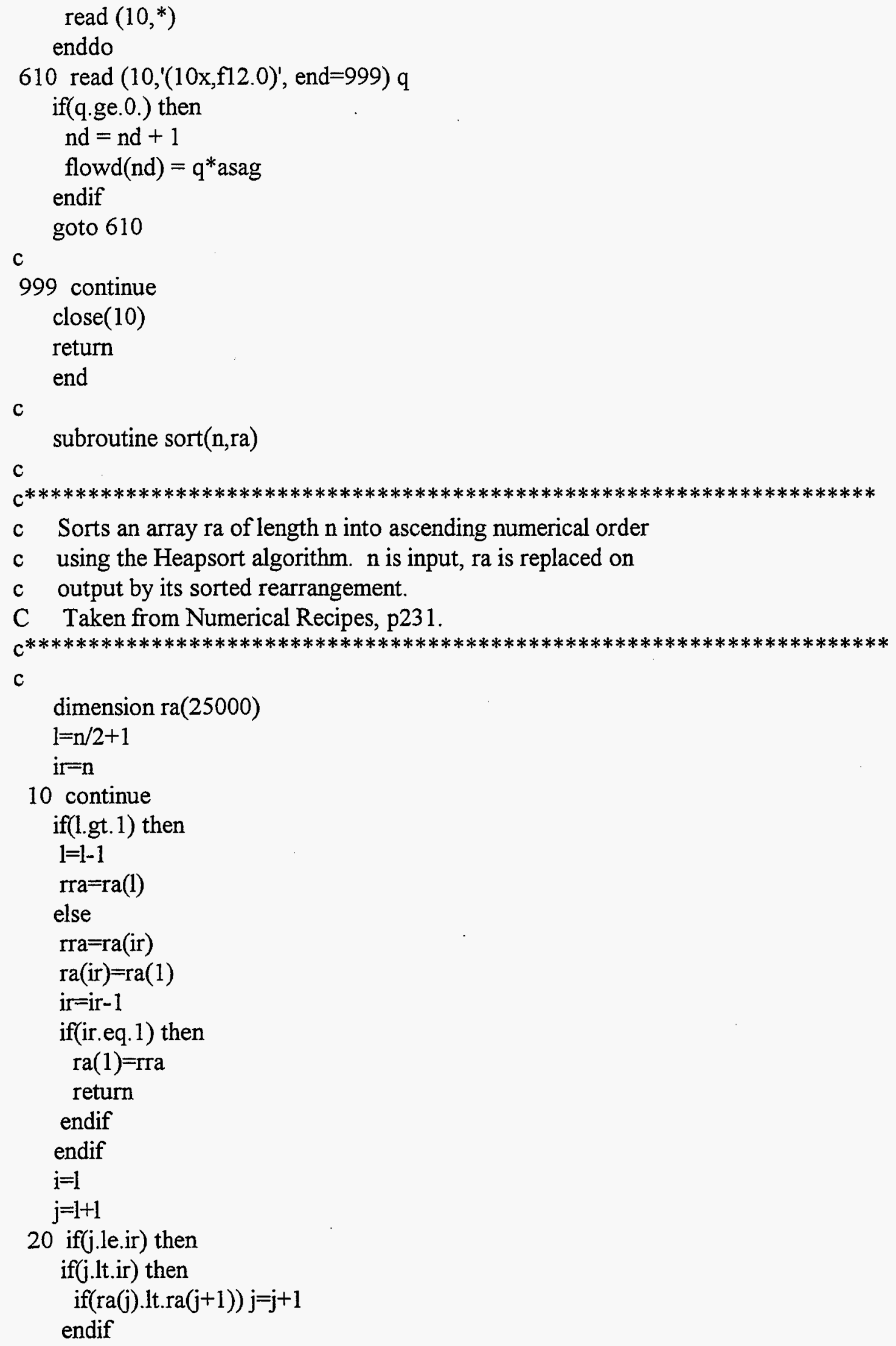




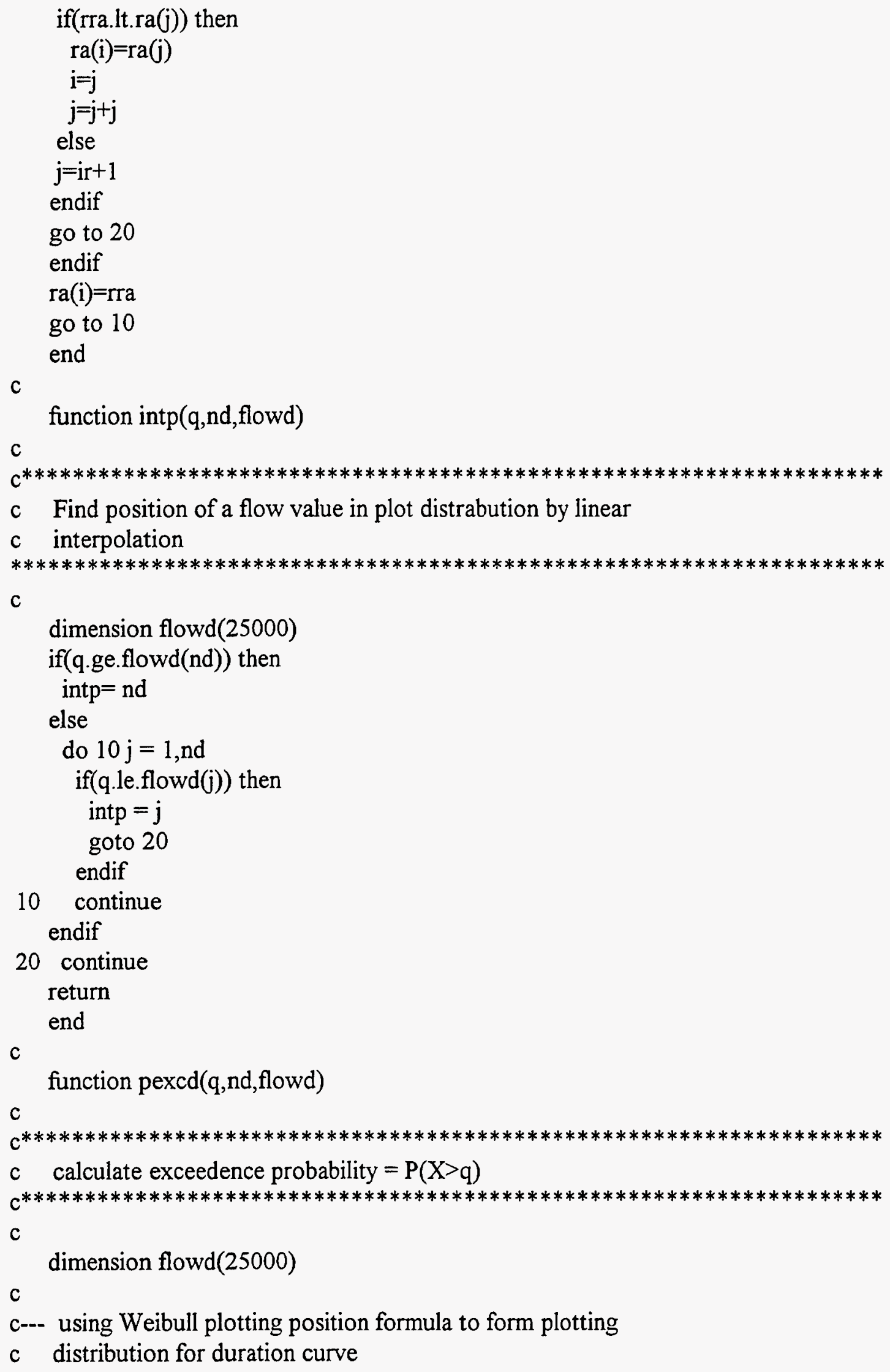


c

pexcd=1.-float(intp $(q$, nd,flowd $)) /($ float(nd) +1 .)

return

end

c

function effvar(q,nh,ne, headn, effin)

C

$\mathrm{c}^{*+1}$

c calculate ratio of power to turbine flow

c

c arguments:

c nh = number of points to define head and flow relationship

c rating curve

c ne $=$ number of points to define efficiency of power generations

c $\mathrm{q}=$ flow

$\mathrm{c}^{* * * * * * * * * * * * * * * * * * * * * * * * * * * * * * * * * * * * * * * * * * * * * * * * * * * * * * * * * * * * * * * * * * * * * * * * * *}$

c

dimension headn $\left(2,{ }^{*}\right)$, effin $\left(2,{ }^{*}\right)$

effvar $=\operatorname{rint}(\mathrm{q}$, ne, effin $) * \operatorname{rint}(\mathrm{q}, \mathrm{nh}$, headn $) / 11.8$

return

end

C

function $\operatorname{rint}(\mathrm{x}, \mathrm{n}, \mathrm{a})$

C

c $* * * * * * * * * * * * * * * * * * * * * * * * * * * * * * * * * * * * * * * * * * * * * * * * * * * * * * * * * * * * * * * * * * * * * * * *$

c linear interpolation

c

c arguments:

c $\mathrm{n}=$ number of data points to define the function

c $\quad a=2-d$ array

c $\mathrm{x}=$ variable

$\mathrm{c}$

C note: no extrapolation

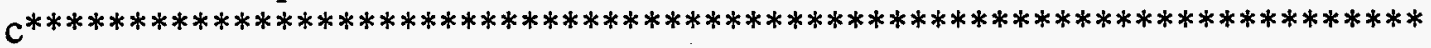

c

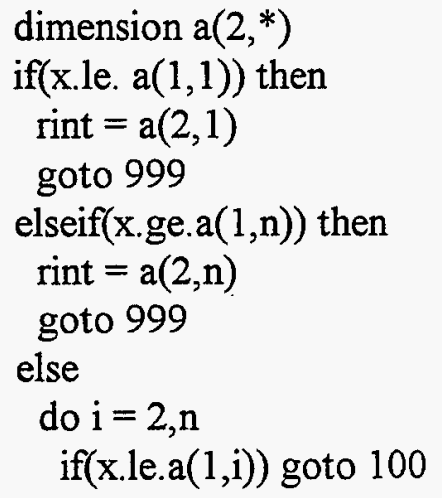


enddo

endif

100 rint $=\mathrm{a}(2, \mathrm{i}-1)+(\mathrm{x}-\mathrm{a}(1, \mathrm{i}-1)) *(\mathrm{a}(2, \mathrm{i})-\mathrm{a}(2, \mathrm{i}-1)) /(\mathrm{a}(1, \mathrm{i})-\mathrm{a}(1, \mathrm{i}-1))$

999 continue

return

end 


\section{Distribution List}

1-5. Y. S. Bao, 1505, MS-6036

6. T. R. Curlee, $4500 \mathrm{~N}, \mathrm{MS}-6205$

7. J. H. Cushman, 1059, MS-6422

8. D. E. Fowler, 1505 , MS-6035

9. S. G. Hildebrand, 1505, MS-6037

10. G. K. Jacobs, 1505, MS-6036

11. P. Kanciruk, 1507, MS-6407

12. J. M. Loar, 1505, MS-6036

13 T. E. Myrick, 4500 N, MS-6253

14-15. R. D. Perlack, 4500 N, MS-6205
16-17. R. M. Reed, 4500 N, MS-6200

18. D. E. Reichle, $4500 \mathrm{~N}, \mathrm{MS}-6253$

18. M. J. Sale, 1505 , MS-6036

19. R. B. Shelton, $4500 \mathrm{~N}, \mathrm{MS}-6205$

20. D. S. Shriner, 1505 , MS-6038

21. Central Research Library

22-24. ESD Library, 1505, MS-6035

25-26. Laboratory Records

27. Laboratory Records, ORNL-RC

28. L. A. Abron, President, PEER Consultants, P.C., 1460 Gulf Blvd., 11th Floor, Clearwater, Florida 34630

29. M. Broido, Director, Environmental Sciences Division, ER-74, Department of Energy, 19901 Germantown Road, Germantown, MD 20874

30. E. G. Cumesty, ORNL Site Manager, Department of Energy, Oak Ridge National Laboartory, P.O. Box 2008, Oak Ridge, TN 37831-6269

31. T. E. Drabek, Professor, Department of Sociology, University of Denver, Denver, Colorado 80208-0209

32-52. Federal Energy Regulatory Commission, Office of Hydropower Licensing, 888 First Street NE, Room 61-23, Washington, DC 20426

53. Michael C. MacCracken, Director, Office of the U.S. Global Change Research Program, Code YS-1, 300 E Street, SW, Washington, DC 20546

54. Office of Assistant Manager for Energy Research and Development, U.S. Department of Energy Oak Ridge Operations, P.O. Box 2001, Oak Ridge, TN 37831-8600

55-56. Office of Science and Technical Information, P.O. Box 62, Oak Ridge, TN 37831

57. A. Patrinos, Associate Director, Office of Biological and Environmental Research, ER-80, Department of Energy, 19901 Germantown Road, Germantown, MD 20874

58. P. R. Rittelmann, FAIA, Executive Vice President, Burt Hill Kosar Rittelmann Associates, 400 Morgan Center, Butler, Pennsylvania 16001-5977

59. S. F. Tierney, The Economics Resource Group, Inc., One Mifflin Place, Cambridge, Massachusetts 02138

60. C. M. Walton, Ernest H. Cockrell Centennial Chair in Engineering and Chairman, Department of Civil Engineering, University of Texas at Austin, Austin, Texas 78712-1076 
Report Number (14)ORNL/TM - -13496

Publ. Date (11)

Sponsor Code (18) DOE/EM; DOE/ER XF

UC Category (19) UC-2000; $E$ UC $-400, D O E / E R$ 